\title{
EEN TIJL UILENSPIEGEL VERHAAL IN DE BOEROETAAL.
}

\author{
DOOR
}

Јон. А. F. SCHUT.

't Verhaaltje, dat ' $k$ hierbij den lezer aanbied is er een uit de velen mij door de schoolkinderen verhaald of voor mij opgeschreven.

Toen 'k in 1905 geroepen werd den Zendingsarbeid op Boeroe voort te zetten kon ' $k$ terstond 'n dankbaar gebruik maken van 't werk door den heer H. Hendriks geleverd, zijn «Het Burusch van Màsarèté» uitgegeven door het Koninklijk Instituut van de T. L. en V. van N. I. 1897.

Door voortdurenden omgang met de bewoners van 't binnenland kwam 'k tot de ontdekking, dat 't werk van den Heer Hendriks voornamelijk betrekking heeft op de taal in 't Mas'rètěsche - de Fènar-Pòlo: de Tien-Stammen, zooals de bevolking van Boere altijd zegt - door 'n deel van de kustbewoners gesproken in hun omgang met vreemdelingen, die zich ook van die taal willen bedienen. Langs 't kustgedeelte der Fènar-Pòlo zijn de meeste menschen tot 't Christendom overgegaan sinds de laatste dertig jaren. $\mathrm{Zij}$ hebben gedurende eeuwen onder invloed van vreemdelingen gestaan. Vooral hebben hier Amboneezen veel gereisd, verbleven er soms jaren; Boeroeneezen trokken telkens voor langer of korter tijd naar Ambon en zoodoende ondervond de Boeroetaal daar langs de kust op ergerlijke wijze den invloed van 't Ambonsche spreek-Maleisch. (Vocabularium van vreemde woorden, voorkomende in het Ambonsch-Maleisch, enz. door G. W. W. C. van Hoëvell. Dordrecht Blussé en van Braam 1876).

Niet 't minst hebben hiertoe bijgedragen de Ambonsche Goeroes, die op de scholen onderwezen, de godsdienstoefeningen leidden en catechetisch onderwijs gaven. Na eenigen tijd bemerkte ' $k$, dat de diensttaal der Goeroes in kerk, catechisatie Dl. 75. 
en school 'n geheel andere was dan die, welke zij in hun dagelijkschen omgang met de Boeroeneezen gebruikten. Hun werd toen ten zeerste aanbevolen in 't dienstwerk toch te spreken zooals zij dit in 't gewone leven met de bevolking gewoon waren, zooals zij de taal van haar leerden. De landskinderen toch hebben de taal, niet de vreemdelingen.

De taal in de Fènar-Pòlo gesproken wordt door de bevolking Liët-emlia: eigen, oorspronkelijke taal genoemd. (liët: taal, e mlia: eigen, oorspronkelijk). Op al mijn reizen door geheel Boeroe' kon ' $\mathrm{k}$ mij steeds van deze taal bedienen en met weinig moeite de dialecten verstaan, die in andere gedeelten van Boeroe dan in de Fènar-Pòlo gesproken worden.

Zoo noem ' $k$ in 't Fògische, de Liët-emtèban: de hakkelende, afgebrokende taal, (eptèbah: afbreken van lettergrepen bij 't spreken) de taal, die in 't Li Sèlasche op de N. kust gesproken wordt. Deze taal heet Liët-Enjòrot. De beteekenis van e njòrot is mij tot heden niet duidelijk. Verder de dialecten van 't Wà Sàma en Kajeli (Gàëli) kustgebied. Deze dialecten hebben gedurende honderden van jaren onder den invloed gestaan van Mohammedanen, vreemdelingen en overheerschers.

Geheel buiten beschouwing kunnen hier blijven die dorpen langs de kust geheel door vreemdelingen, Galẻla's, Boetonneezen, Soelaneezen. enz. bewoond, waar nog steeds de talen van 't land van herkomst gesproken worden.

Naast de Liët-emlia treft men aan de Li' Gàran de jachttaal, die alleen in 't Gàran jachtgebied in 't Westen van Boeroe mag gesproken worden. De constructie dier taal is dezelfde als die van de Liët-emlia, alleen gebruikt men geheel andere woorden. Dit andere woorden bezigen heet ribah. Vele woorden in de $\mathrm{Li}$ ' Gà ran komen in de Liët-e n jò r o t dikwijls voor als gewone spreektaal.

Voorts is voor menstrueerende meisjes de liët-epkòit in gebruik waarin ook weer vele woorden der Liët-enjòrot voorkomen. (e pkòït $=$ taboe, saäli, van kòïn: geest die vereerd wordt en gevreesd),

Door den grooten omvang van mijn arbeid als Zendeling was ' $k$ helaas niet in staat zooveel krachten en tijd aan taalkundige werkzaamheden te geven, dat ik de verschillende dialecten aan 'n vergelijking kon onderwerpen, die zoo hoog noodig is. 
Daar er onder de Ambonsche Goeroes eenigen waren, die hun eigen landstaal steeds onder elkander spraken, kon 'k met hen vaak treffende overeenkomsten constateeren tusschen de Liët-emlia en de Ambonsche landstalen. Mocht ik steeds gebruik maken van 't geen door de Heeren van Ekris en van Hoëvell over die talen is geleverd, vaak werd ik teleurgesteld en kan ik 't niet nalaten ook hier mijn spijt uit te drukken, dat er omtrent die talen nog zoo bitter weinig bekend is en dit te meer, daar de Ambonsche talen binnen niet langen tijd zeer zeker tot «de doode» zullen behooren.

Mocht de Regeering toch spoedig ingrijpen en 'n taalgeleerde naar de Ambomsche eilanden zenden om daar op taalgebied voor de wetenschap te redden, wat nog gered kan en moet worden.

Hier en daar gebruikte ik afkortingen om de Ambonsche talen aan te duiden waarmede werd vergeleken. Kkk. Kaibobo; T. Tihoelale; R. Roemah kai; H. Hata soewa; W. Wai Samoe; K. Kamarian; Sap. Saparoea; N. Noesa laoet; Asil. Asiloeloe; Har. Haroekoe; Hil. Hila; Pi. Piroe; S, bergdorpen Serang. (Ceram).

Joh. A. F. Schut.

Zendeling-leeraar U. Z. V. 


\section{Harkajàte fil Kà Lampo.}

Toean-Ko-Làtoe sà dàboah nak fàfor ědemen.

Lalen sà Toean-Ko-Làtoe di dàsioek nak àtar pol'pa fèneh: kim ik'kalak Kà Lampo e là rin dàbàboah nang fàfor na e.

Bèko nak àtar pol'pa doeikoh pà doekalak Kà Lampo e. Kà Lampo dàenikah fèneh; wàhang sàpan ne kim doebàkalak kàno?

Àtar pol'pa di doeëprèpak fèneh: Toean-Ko-Làtoe dàbàkalak kà. Bèko Kà Lampo dàhaïh ro.

Là betoen sir doesoeb' dàteh haïk Toean-Ko-Làtoe dàfètekengeïh Kà Lampo e fèneh: loek boah nang fàfor na penik ke. Bèko Kà Lampo dàikoh pà dàpoenah liat òto moea e pa dàibik fàfor di e.

Lalen sà Kà Lampo dàhòsak-soep-soepak toe dàëpmàtah-sàtaïk fàfor di e, béko rin dáegoeh ikoenno pà dàik'-sẻkak korro òto káboet te

Bisoek fil di rin dàikoh toe dàëprèpak-làhah Toean-Ko-Làtoe e fèneh: nam fàfor paskemak doemòdoh-hònot-hanoeh haïk fidi kàboet te.

Wahang di sir doeik'kalih kàboet te boe sir doebetah rahek fàfor-ikoen no.

Bèko Toean-Ko-Làtoe e dàolih toe dàsioek nak àtar pol'pa pà doeik'làtah oeka pà doegàroeh ěroengan sà.

Là betoe sir doepoen'mátak haïk ěroengan di e, sir doeòsok Ká Lampo e òto erroengan lalen ne pà doeik'pòlok ke fidi olat te.

Bèko sir doelèbah he gam lalat te toe doetatik penik ke fi di ta pà doeolih-egoeh-làfat toe doebarbâk-emsik-emsikan Kà Lampo e.

Là betoen dibědih he g'emtoeat sà dàegoeh nak kòkol pà dàik'tàgah-hètak. Là betoe Kà Lampo dàkitah he rin dàëprépak fèneh: g'emtoeat e.! gam mahek là koe òsoh sà bòbòbok bah na là à ik'esteīh penik, bàmah moh do jàko esteīh-bâk ToeanKo-Làtoe nak ĕroengan ne.

Gamdi g'emtoeat di dàòsoh fi di ěroengan lalen ne toe Kà Lampo dàsoebah toe dàhèkah.

Soep-soepan do àtar pol'pa di doekadoek toe doelèbah g'emtoeat di e pà doepòlok ke, boe g'emtoeat te dàlaoen fèneh: 
oreh kàneh! àtar pol'pa jàko do Kà Lampo mélah, toe Kà Lampo dàhèkah haïk.

Boe àtar pol'pa di doesàdeh fèneh: mèlah gah! kaë do Kà Lampo rèsek ke, kaë niak kami!

Bèko sir doeik'pòlok g'emtoeat te.

Bisoek fil di Kà Lampo dàik' fòìh fidi màsi e.

Là betoe rin dàolih haïk rin dàeprépak-làhah Toean-Ko-Làtoe e fèneh: Toean-Ko-Làtoe nam àtar pol'pa doepòlok kàno běbetah fi di nam àma-nitoe sirro nam ina-nitoe noen eskàkoet te. Toe nam ina sirro nam àma doeëprépak fèneh: kaë hẻlen-hẻlen gam lawek.

Béko Toean-Ko-Làtoe dasioek nak àtar pol'pa fèneh: kim gàroeh nang eroengan sà. Gamdi nak àtar pol'pa di doepoenah ĕroengan sà toe doeòsok Toean-Ko-Làtoe e fi di ěroengan lalenne, bẻko sir doëptànak ke gam lawek. Bẻko sir doesàhih etah esnègen lawe-lawe toe sir doeëprèpak fèneh: pòlok ke fi na bẻkah!

Gamdi sir doepòlok Toean-Ko-Làtoe e.

Toe Kà Lampo dàolih toe dàalah Toean-Ko-Làtoe nak fin' har ro toe Ka Lampo emsikan dàpoena Toean-Ko-Làtoe.

\section{Anekdote over Kà Lampo.}

'n Vorst fokte veel varkens. Eens beval die Vorst z'n veertig slaven zeggende: gij gaat Kà Lampo roepen dat hij deze mijn varkens fokke. Hierop gingen zijn veertig slaven om Kà Lampo te roepen,

Kà Lampo vroeg zeggende: waarom roepen jelui mij ?

Die veertig slaven spraken zeggende: Meneer-de-Vorst roept U. Hierop volgde Kà Lampo ze.

Nadat zij aangekomen waren beval de Vorst Kà Lampo zeggende: jij fokt deze mijn varkens maar. Hierop keerde Kà Lampo terug om kotten in het bosch te maken om die varkens op te passen. Eens stond Kà Lampo zeer vroeg op en doodde al die varkens, nam daarna hunne staarten om die in den modder te gaan stoppen. Toen dit geschied was ging hij en sprak tot den Vorst zeggende: al uw varkens zijn gesmoord in den modder. Daarom ginnen zij in den modder graven maar zij vonden slechtș de varkensstaarten.

Hierop keerde de Vorst terug en beval zijn veertig slaven bamboe te gaan hakken om 'n koț te vervaardigen. 
Toen zij dat kot gereed gemaakt hadden deden zij Kà Lampo in het kot om hem te gaan verdrinken in de zee.

Hierop droegen zij hem naar het strand en zetten hem daar eerst neer om leeftocht te gaan halen en lieten Kà Lampo alleen achter.

Op dien zelfden tijd nam 'n oud man z'n korfje om bij laag water te gaan visschen. Toen Kà Lampo hem zag sprak hij zeggende: $\mathrm{O}$, oude heer! kom hier ga 'n oogenblikje hier binnen dat ik eventjes m'n behoefte doe, wanneer ge 't niet doet dan bepoep ' $k$ hier het kot van Meneer den Vorst.

Alzoo ging de ouwe man in het kot en Kà Lampo ging naar buiten en vluchtte.

Den volgenden morgen vroeg dan kwamen die veertig slaven en droegen dien ouden man weg om hem te verdrinken, maar de oude man jammerde zeggende: ai mij! veertig slaven, ik ben Kà Lampo niet, en Kà Lampo is reeds gevlucht.

Maar die veertig slaven antwoordden zeggende: 't is niet waar! jij bent Kà Lampo wèl, jij bedriegt ons!

Hierop gingen zij den ouden man verdrinken.

Nadat dit gebeurd was ging Kà Lampo in de zee baden. Toen hij teruggekomen was sprak hij tot den Vorst zeggende: Meheer-de-Vorst uw veertig slaven verdronken mij juist op het dak van wijlen uw vader en moeder. En uw moeder en vader spraken zeggende: gij moet heel gaauw naar zee komen.

Hierop beval de Vorst zijn veertig slaven zeggende: jelui maken mij 'n kot. Alzoo maakten die vertig slaven 'n kot en deden den vorst in het kot, daarna brachten ze hem naar de zee.

Hierop roeiden zij tot daar waar geen land meer te zien is (zeer ver in zee) en zij spraken zeggende: dompel hem hier maar onder! Alzoo verdronken zij den Vorst.

En Kà Lampo keerde terug en nam de vrouwen van den Vorst en Kà Lampo zelf werd Koning. 


\section{Harkajàte ') fil ${ }^{2}$ ) Kà Lampo. ${ }^{3}$ ) Anekdote over Kà Lampo.}

1). Harkajàte: grappig verhaál, anekdote Mal. hikajat.

Onder deze grappige verhalen bekleeden die over Kà Lampo of Siri bòdoh den Boeroeschen Tijl Uilenspiegel 'n groote plaats.

Verder komen in de ongeschreven proza-literatuur van Boeroe voor enritat: verhaal, vertelling, ěritah: vertellen, verhalen, Mal. tjerita; endòhin: geschied verhaal, geschiedenis, 'n ware gebeurtenis, édòhih: verhàlen, vertellen 'n geschiedenis, 'n ware gebeurtenis; àsal: verhaal omtrent de voorouders en datgene wat met hen samenhangt, Mal. asal; kàriget: gelijkenis, rigeh: iets op iets of iemand anders in 'n gelijkenis toepassen.

2). fil: over.

fil jàko: over mij; jàko: ik is de dubbel emphatische vorm van 't person. vnw. $1^{\circ}$. pers. enklv. $1^{\circ}$. naamval à: ik, zie 24 ;

fil kaë: over u; kae: gij, emphat. vorm van kà: gij.

fil rinne: over hern, haar; rinne: hij, zij, emphat. vorm van rin: hij, zij;

fil kami: over ons, exclusief.

fil kita: over ons, inclusief.

fil sirroea: over hen tweeën;

fil sira: over hen, over haar;

fil kimi: over u lieden.

Men zou dus in 't Nederl. kunnen zeggen dat 't voorzetsel fil: over, den Nominatief bij zich heeft, zie 24 .

Dit is niet 't geval met 't voorzetsel fili: van, dat waarschijnlijk van fil: is afgeleid fil $+\mathrm{i}$.

fili káno: van mij, kàno: persnl. vnw. $1^{\circ}$. pers. enklv. accus.

fili kà: van u, kà, accus van kaë.

fili he: van hem, haar;

fili kami: van ons, exclus.

fili sirroea: van hen, getweeën; van haar getweeën;

fili ro: van hen, van haar;

fili kimi: van u lieden,

filim: van af, heeft de zelfde persn. vnw. in nominat. bij zich als fil: over.

filim do: vanaf waar, van waar; vaak bij 't vlug spreken verkort: fil do; filim daë: vanaf landkant, van de landzijde; filim saka: vanaf boven, van boven. 
3). Kà Lampo: De beteekenis van dit woord is mij nog niet bekend. Volgens sommigen zou 't eigenlijk moeten zijn ka ram'pôh: samengesteld uit kà: die + ràman: oog + pôh; wijd open van de oogen ( $r$ en 1 wisselen meermalen af loea en roea: twee, là to en ràtoe: vorst) $\mathrm{ram}$ ' $\mathrm{pôt}$ : koloog; de beteekenis zou dan zijn: die groote oogen op doet zetten. In de Ambonsche dialecten heet Tijl Uilenspiegel Siribòdo, 'n naam, die ook op Boeroe voorkomt. De beteekenis van Siribòdo is mij niet duidelijk.

Toean ${ }^{4}$ ) Ko Làtoe ${ }^{5}$ ) $\mathrm{sà}^{6}$ ) dàboah ${ }^{7}$ ) nak ${ }^{8}$ ) fà for ${ }^{9}$ ). Meneer de Vorst 'n fokte zijn varkens 'n Meneer-de-Vorst fokte zijn vele varkens. ědemen ${ }^{\mathbf{1 0}}$ ).

vele

4). Toean: Mal. Meneer;

5). Ko Là toe samengesteld uit ko +1 à to e; là to e of ràt o e: vorst. In de L. E. of Boeroetaal. (Liët-emlia: taal oorspronkelijke, oorspronkelijke, landstaal. Verkrt. L. E.) is vorst lèber; de è uit te spreken als i gelegen tusschen pik en pek in de Hollandsche uitspraak, 't meest overhellend naar de $\mathrm{i}$. 1 à to e, R. T. Hr. H. W. Kbb. Pi. S. Sap la o el, N.

Ko: Hiervan zegt Prof. Kern. Fidji enz. blz. 29, 3. Aanwijzende woorden; "ko laat zich vergelijken met Idon. si, of zooals sommige talen hebben is.

De L. E. heeft dit $\mathrm{i}$ als aanwijzend woord in bijv. ka ë $\mathrm{I} \mathrm{ha}$ : gij de groote, bij 't aanspreken van den vorst of iemand dien men eer bewijzen wil.

Toean Ko Làtoe is een accenteenheid, "meneer de Koning". Dit blijkt ten duidelijkste uit sà, een, 'n. dat volgt. De vertaling is ook: "'n Meneer-de-Koning".

$\mathrm{Ko}$, komt verder voor in uitroepen als à $\mathrm{mako}$ ! vader! in à $\mathrm{o}$ ! moeder! welke vormen liever, zachter zijn dan à $\mathrm{m}$ a $\mathrm{n}$ ! i n $\mathrm{n}$ ! vadèr! moedèr ! à $\mathrm{m} a+\mathrm{n}$, vader van spreker spreekster, i $\mathrm{a}+\mathrm{n}$ : moeder van idem. Kern. Fidji blz. 29 r. 18 v. o. en vlgd. "Evenals $\mathrm{si}$ in 't Indon. wordt ko ook gebezigd bij verwantschapswoorden, om de natuurlijke reden dat deze het karakter van eigennamen dragen. Men zegt zoowel a tamangku, mijn vader, als ko ta mangku. Uit eene opmerking van Hazlewood leeren wij dat de zendeling Cargill 't eerste "meer gepast» achtte dan het tweede, hetgeen Hazlewood niet toegeeft. Het komt mij voor, dat Cargill door een fijn taalgevoel geleid werd; 
ko tamangku moge veelvuldig gehoord worden, oorspronkelijk is het $\mathrm{m}$. $\mathrm{i}$ een soloecisme; $\mathrm{ko} \mathrm{tama}$ zou volkomen in den haak wezen, evengoed als Jav. si bapa, en zoo ook a tamangku, O. J. ramangku, maar ko tamangku strookt niet met het M. P. taaleigen».

In de L. E. worden de aanwijzende woorden geplaatst achter 't woord, dat zij aanwijzen.

Verder komt ko nog voor in den uitroep wàtihko: ontfermer! wàtihko, moesik kà no ! ontfermer, heb medelijden met mij !

6). Sà: een, 'n; s a ne, K. T. R. H. W. Kbb., sa i, Sap. N., sa, a is a Asil., sa, Har., is a i, sa, Hil., is a, K. T. R. H. W. Kbb., saa, wasa, Pi., esa, S.,

$\mathrm{S}$ à kan men 't beste weergeven met 't Holl. 'n; gè bah s à, 'n mensch; ho ema sà, 'n huis; wàga sà, 'n prauw; la len $\mathrm{s}$ à, keer 'n, 'n keer, eens.

Bij 't opnoemen der getallen zegt men ook sà, een, roea, twee, tè lo, drie, enz.

Van dit sà heeft men de afleiding sia. We hebben hier de invoeging van 't aanwijzende woord $i$; de beteekenis is dan: dat een, het een, vandaar deel, gedeelte, rest, en dit in uitdrukkingen als sia doebàdèfoh 'n deel, 'n gedeelte, 'n rest blijven bijv. van 'n troep menschen waarvan 'n aantal vertrokken. Sia doebà̈len, 'n deel resteeren, bijv. van vruchten waarvan 'n aantal is opgegeten, gestolen.

In dergelijke uitdrukkingen staat 't werkw. steeds in den meervoudsvorm met doe wat bewijst dat sia als 'n plur moet opgevat worden. Blijft er maar één over dan gebruikt men nooit sia maar altijd emsian: zijnde de een er van.

Van sia wordt door gedeeltelijke woordherhaling gevormd 't woord si-sia, 't welk de beteekenis heeft van e enig wanneer er bijv. sprake is van 'n kind, 'n zoon, 'n dochter. $\mathrm{Nak}$ à $\mathrm{nat}$ si-sia, zijn eeniggeboren kind, haar eeniggeboren kind, wat naar 't zinsverband kan zijn, zijn, haar eenige zoon, eenige dochter.

Ook komt si-sia voor in de beteekenis van 'n enkele.

Wanneer men bijv. vraagt:

oek dàbà à jih e plaoes kopin pila?

gij noodig hebben naald oog hoeveel.

Hoeveel naalden hebt gij noodig?

$$
\begin{aligned}
& \text { si-sia rahek. } \\
& \text { 'n enkele slechts, }
\end{aligned}
$$


één enkele slechts; één slechts moet vertaald worden met emsian rahek wat letterlijk vertaald zou luiden em: zijnde, sia, 'n deel, één, n, ervan, zijnde een er van slechts.

Van emsian is door invoeging van kgevormd't woord emsikan: alleen, jàko emsikan: ik alleen, rinne emsikan, [hij, zij, alleen.

Door gedeeltelijke woordherhaling emsik-emsikan heeft men 'n versterkte beteekenis van alleen, totaal alleen, geheel alleen.

o ek dàbàgàroeh he emsik-emsikan.

gij werken het totaal alleen.

à hèkah emsik-emsikan.

ik vluchtte totaal alleen.

7). dà b o a h :

In de L. E. benoemt 't werkwoord in zijn oorspronkelijken vorm de handeling die reeds verricht is of die welke nog verricht moet worden; de laatste is dus de bevelende vorm.

boah: fokken, opvoeden, is dus de benaming van de handeling die reeds heeft plaats gehad, wat hebt gij gedaan? wat waart ge bezig te doen? fokken, opvoeden: boah; of de benaming van de handeling, die nog verricht worden moèt, wat moet ik, gij, hij, zij, doen? fokken, opvoeden: boah.

Op de vraag aan mij gedaan: wat deedt gij? wat waart ge bezig te doen? met den nadruk op deedt moet ' $k$ antwoorden ik fokken, opvoeden: à boah; wat wij dus in 't Nedrl. te vertalen hebben met ik fokte, ik voedde op.

Met den nadruk op gij, wat deedt gij ? wat waart gij bezig te doen? moet 'k antwoorden jàko boah, jàko: dubbel emphatische vorm van à $\mathrm{ik}$ voedde op; ik fokte.

Op de vraag: wat $\cdot$ doet $g$ ij ? waar zijt gij op dit oogenblik mede bezig? kant ' $\mathrm{k}$ niet antwoorden à $\mathrm{b} o \mathrm{a} h$ want ' $\mathrm{k}$ ben nog bezig de handeling van fokken, opvoeden te verrichten. Hierop moet 'k antwoorden à bàboah: ik fokken, opvoeden, ik fok, ik voed op.

We hebben hier dus 't prefix bà + boah, fokken, opvoeden. 't Prefix bà stelt vast, dat de handeling of werking verricht wordt, dat men er mede bezig is.

Bij qualificatieve woorden duidt 't prefix bà aan, dat de eigenschap in 't qualificatieve woord genoemd in bijzondere mate aanwezig is bij 't woord dat de qualificatie uitdrukt:

$$
\text { ië sà bàgòsa. }
$$

ding 'n goed, 
'n extra buitengewoon goed ding, zoo goed 'n ding! gèbah sà bàha: mensch 'n zoo groot;

bà is oorspronkelijk 'n werkwoord, met de beteekenis van: aanwezig zijn. Op de vraag rin fi do? hij te waar? Waar (is) hij? antwoordt men rin bah na: hij aanwezig (is) hier, rin bah fi na: hij aanwezig is te hier, hij is hier; kim fi do? gijlieden te waar? Waar zijt gij, antwoordt men: kami bah na: wij aanwezig hier, wij zijn hier, kami, wij exclusief.

rin dà màtah bah na, hij stierf aanwezig zijnde hier, dat is, hij stierf hier op de plaats waar spreker zich nu bevindt. à bàdèf' bâk, samen gesteld uit à: ik, bàdéfoh: ben bezig met blijven, blijf; bâk: hier op de plaats waar ' $k$ mij nu bevind. $\mathrm{k}$ de transitief $\mathrm{k}$ achter vele transitieve werkwoorden.

epte' bak, samengesteld uit epteah: zitten + bak: hierzitten, op de plaats waar men zich bevindt; bag' bak, samengesteld uit bàgeh: liggen, slapen + bâk: hier liggen, hier slapen, op de plaats waar men is.

't Werkwoord met 't prefix bà, geeft dus te kennen, dat de handeling of werking verricht wordt op de plaats van 't subject of spreker. Dit kan 'k dus alleen maar van mij zelf zeggen.

We zouden geneigd zijn bàbo $\mathrm{a} h$ in 't Holl. te vertalen met 't deelwoord: fokkende, opvoedende maar deze beteekenis heeft bàboah niet. De L. E. heeft voor 't deelwoord 'n eigen werkwoordelijken vorm emboah.

Van 'n ander sprekend kan 'k niet zeggen bàboah zonder meer, want de handeling of werking wordt niet bij spreker, bij mij, verricht maar bij 'n ander. 'k Moet dan zeggen oek gij dà bàboah: dà zijt ('t) dàboah: fokken, opvoeden aanwezig is; gij zijt ('t) bij wien 't fokken, 't opvoeden aanwezig is, verricht wordt. gij fokt, gij voedt op;

rin dàbà bo $a h$ : hij, zij, fokt, voedt op;

K a mi dàbà bo o h: wij exclusief voeden op, fokken,

N.B. 't exclusieve $\mathrm{kami}$ wordt in de L. E. steeds als 'n Enkelvoud opgevat.

kit a do ebàbo a h: wij (inclus.) fokken, voeden op;

sir roea doebàboah: $\mathrm{Zij}$ getweeën fokken, voeden op,

kim doebàboah: gijlieden fokt, voedt op.

De letterlijke beteekenis is dus gij zijt, hij, zij is, wij zijn enz. de persoon of de personen bij wien, wie de handeling van fokken, opvoeden aanwezig is. 
Wanneer ' $k$ tot iemand de vraag richt: fokt gij, of omtrent 'n derde vraag: fokt hij? dan vraag ' $k$ inderdaad of de handeling van fokken bij $U$, hem, haar, enz. aanwezig is.

o ek bàboah: gij de handeling van fokken aanwezig? fokt gij? rin bàboah: hij fokken? fokt hij, zij ?

kami bàboah: wij (excl.) fokken?

kita bàboah: wij (incl.) fokken?

sirroea bàboah: zij getweeën fokken?

sir bàbo $\mathrm{a} h$ : zij fokken?

ki m bàboah: gijlieden fokken?

't Antwoord hierop is, dat de handeling bij mij, u, hem, haar enz. aanwezig is oek dàbàboah; gij fokt; rin dàbàboah: hij, zij fokt enz. voor pluralis doe.

Uit ' $t$ zinsverband moet evenwel blijken of 't praesens of imperfectum in de vraag bedoeld is. oek bàboah? kan dus in den zin zin zoowel beteekeneu is 't fokken nù, praesens, bij $\mathrm{u}$ aanwezig, verricht gij nu die handeling of wàs 't fokken imperfectum bij u aanwezig, verrichtet gij toen de handeling van fokken. Aangezien 't werkwoord in zijn eenvoudigen vorm de handeling of werking aanduidt moet ' $k$ als 't mij zelf betreft antwoorden à boah: ik fokken; ik fokte:

o ek dàboah: gij zijt (degene bij wien) 't fokken als volbrachte werkzaamheid (was) gij foktet; rin dàboah: hij, zij fokte, kami dàba o h: wij (incl.) fokten; kita doeboah: wij (incl.) fokten; sir roea, sir, kim doeboah. Zij getweeën, zij, gijlieden fokten, foktet.

o ek bàkah-pàla? gij eten rijst (bàkah-pàla samengesteld uit $\mathrm{kah}$ : eten + pàla: rijst is één accenteenheid) antwoord ik à bà kah-pà la: ik rijst eten, ik eet rijst, of à kahpà la: ik rijst eten (imperfect.) ik at rijst.

ò ek bàkah-pàla, met ò ek: gij waarop de klemtoon valt antwoordt men: jàko kah-pà la: ik eten rijst, ik eet rijst of ik at rijst naar 't zinsverband.

dà voor 't enkelvoud, doe voor 't meervoud hebben in de L. E. de beteekenis van zijn;

jàko dà ewàsa: ik ben rijk; tò hon ne dà rema: weg, de is lang, de weg is lang; kimi doe kàròsa: gijlieden zijt onbeschoft. hoemar ro doe ha: huizen de zijn groot, de huizen zijn groot; nit oe Tesi-tàma dà emloebà, wijlen Tesi's-vader was mild; gèb' eplàtat to paskemak doe 
eflaoe: soldaten de allemaal zijn, waren afgemat, al de soldaten zijn, waren afgemat.

boa $h$. Zeer vele verba eindigen in den actieven vorm op $h$. Van 'n groot aantal dezer verba verandert deze $h$ in ' $n k$ wanneer 't werkwoord in den zuiveren actief-transitief vorm wordt gebruikt en 't woord waarop de handeling betrekking heeft volgt. Dit is ook 't geval in die elliptische zinnen waarin 't object is weggelaten dus in den bevelenden vorm.

sėkah: steken, steek! steekt! sèkak ke: steek(t) hem, haar, het! sẻkak! steek, steekt (hem, haar, het).

sẻkak bẻkah : steek, steekt (hem, haar, het) maar, steek steekt maar!

fò to h: kerven, snijden, fò to k ke: kerf, kerft, snijd hem haar, het, fòtoh: kerf! kerft, snijd! snijd, kerf, kerft, met weglating van 't object als bekend.

こ̌nikah: vragen, vraag! vraagt? Łnikak: iemand ergens om vragen, vraag, vraagt iemand om iets!

sėkak kor: steek, steekt ze (onbep.) sè kak kor ro: steek steekt ze de, bepaald, steek, steekt hèn, haar.

Voorbeelden van verba op $h$, die oorspronkelijk intransitief zijn: angah: zien, angah do: zie toch! kijk eens!

aweh: hellen; bágeh: liggen; beroeh: knakken, van zelf, 'n takje; bidoh: met 'n werpnet visschen; als men in 't Holl, zeggen kon moest men vertalen: werpnetten; bobih: horizontaal heen en weer zwaaiën; boeleh: onophoudelijk weenen; kalih: graven; deah: rusten; dareh: leunen; dèfoh: blijven; doeleh: blaffen; bà $\mathrm{a} h$ : van boven neer zien, kijken; egràg $\mathrm{a}$ h: huilen van honden; eprè pah: praten, spreken; gò $\mathrm{r} a \mathrm{~h}$ : razen, tieren; hẻkah: vluchten; hèsah: hijgen; kèhah: stijgen; midih: spelen; neweh: leven; oah: bewegen van 't water, in 'n glas bijv.; òpih: blazen v. d. wind; (òpih: rooken van tabak is transit.) òsoh: binnen gaan; pànah: springen; rereh: stranden; $\mathrm{s}$ à o $\mathrm{e} h$ : aanzamelen in den grond, bijv. aardappelen; s à $\mathrm{pa} h$ : haken; sèheh: op zij gaan; tangih: weenen; teah: staan; tenoeh: week worden door water; weah: op en neer schommelen; wiloh: heen en weer schommelen;

Voorbeelden van verba op $h$, die oorspronkelijk transitief zijn:

in oh: drinken; eflalih: staan; sò pih: schillen met 'n mes; rosih: knagen van muizen; fòkih: inwikkelen; doleh: goed met goed vergelden; g a w eh: vasthouden; ef rà keh: grijpen; 
egoeh: nemen; kah: eten; làhah: vragen: kitah: zien; lo e fa h: uittrekken, kleeren; nà kah: zich verwonderen over;

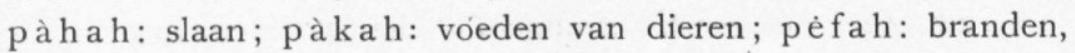
schieten; tàhah: omhakken; tirah: manen om schuld; simah: beknorren; tèfo e h: lossen; wàd a h: op den schouder dragen; w è $n$ e h : zingen.

Voorbeelden van wezenlijk reflexieve verba op h.

fòi h: baden; à bàfòih kàno: ik baad mij; mòtih: koude koorts hebben; à bàmotih kàno: ik koude koorts mij; ik heb koude-koorts; e r $\mathrm{rà} \mathrm{rah}$ : heete koorts hebben; à bà ěr $\mathrm{r}$ r $\mathrm{rah}$ $\mathrm{k}$ à n o : ik heete koorts mij, ik heb heete koorts; makà sah : dorsten, à $\mathrm{bàmakà} \mathrm{sh}$ kan $\mathrm{o}$ : ik dorst mij, ik heb dorst; e glàd a h: hongeren; à bà eglàd a h kàn o: ik honger mij, ik heb honger.

Voorbeelden van oorspronkelijk intransitieve verba op $\mathrm{k}$.

erak: kloppen van 't hart; kerek; staan; labak: vliegen; lòlok; aanspoelen; mangik: opdrogen der borsten; wàtak: grootspreken.

Voorbeelden van oorspronkelijk transitieve verba op $\mathrm{k}$.

afik: zolderbalken vastmaken op de liggers; alik: schillen; atek: met atap dekken; amoek: den strot met medicinale bladeren wrijven; apak: eten geven aan de geesten der voorvaderen; ěnilik: overschenken; leak: bewaren, opbergen; ibik: bewaken; ipik: in pand nemen; katoek: zenden; moesik: medelijden hebben met; nanoek, ěnanoek: overleggen; òdok: nasporen; pépek: drukken, plat drukken; pihik ophangen; torik: kluiven; wà ak: drogen in de zon.

Afgeleide transitieve verba op $\mathrm{k}$.

a ng a h, a ng a k: kijken naar, bezien; bàge h, b a g e k: beslapen; bàgek-tòron: vast slapen; beroeh, beroek: knakken iets; bidoh, bidoek: met 'n werpnet visschen iets; bobih, bobik: 't erf met 'n kapmes schoonmaken; boeleh, boelek: iets voortdurend beweenen; kalih, kalik: iets in of iets uit graven; dareh, darek: iets doen leunen; doeleh, doelek: tegen, om iets blaffen; bà $\mathrm{a} \mathrm{h}, \mathrm{b}$ à $\mathrm{ak}$ : van bovenop iets neer zien, kijken; egoeh, egoek: opbeuren en meenemen; eprèpah, eprèpak: over iets tegen iemand praten, spreken; gòrah, gò rak: over, tegen iets razen, tieren; h'èsah, hès a k: iets trekken; làh ah, làh ak: leenen; kèhah, kèhak: iets doen stijgen, ophalen 'n zeil; midih, midik: ergens mee spelen, 
bespelen 'n instrument; ò pih, òpik: aanblazen vuur; ò soh, ò so k: ergens binnen gaan, iets doen binnengaan; rereh, rerek: doen stranden; safoeh, safoek: in menigte uitstrooien op den grond, zaaien; sà pah, sàpak: iets inhaken; sèheh, sèhek: op zij doen gaan; tangih, tangik: beweenen; teah, teak: planten; weah, weak: op en neer schommelen; wiloh, wiloe k: heen en weer doen schommelen, schoppen met den voet.

N. B. Men ziet, dat de verba met o, bij den transit. vorm, deze o veranderd hebben in o e.

Voorbeelden van afgeleide transitieve verba op k, die 'n plaats aanduiden waar de handeling verricht wordt.

deah: deak: ergens rusten; dėfoh, défoek: ergens blijven bewonen; bah, bâk: op de plaats van spreker; epteah: zitten epteak: ergens op zitten, bezitten; areh: tegen over zijn, a rek: zitten tegenover zijn bord aan tafel ò soh, òsok: ergens binnen gaan.

Voorbeelden van afgeleide transitieve verba op $\mathrm{k}$ die meestal gebruikt worden met to ehà: er mede, eflalih slaan eflahik to eha: er mede slaan; fòkih, fòkik toehà: er mede inwikkelen; efràkeh, efràkek toehà: er mede grijpen. Tàhah, tàhak: omhakken met; tirah, tirak: manen met door middel van; pèfah, pėfak: schieten met; afschieten (geweer).

Voorbeelden van accidenteele werkwoorden die oorspronkelijk eindigen op $\mathrm{k}$.

delak: breken van 'n touw, draad; difoek: verloren gaan; dèlnaïk: verstrooid liggen.

Voorbeelden van afgeleide accidenteele verba op $k$, met ' $t$ prefix eg.

eglidoek: iets vergeten, transit.

eglalak: verdwijnen van wolken, intranst.

e g hà pa k: geopend zijn van den mond bij 'n lijk van mensch of beest; intranst.;

eglisik: schaven van de huid; trans.;

egroeroek: toevallig uitstorten; trans.;

e griak: opschrikken in den slaap, trans.;

eghònok: plotseling wegsluipen van 'n slang, intrans.;

eglòlok: bijna op zijn van vruchten, intrans.;

egrònok: gesmolten zijn; intrans.;

egja oek: per. ongeluk uitstorten, trans.;

e gròhok: uitvallen van 't haar, intrans. 
Voorbeelden van 'n wezenlijk reflexief werkwoord op k. transitief.

gè t e k: kortademig zijn, à f bà gè te $\mathrm{k}$ kà n o: ik kortademig mij, ik ben kortademig bisoek z. 38 .

Voorbeelden van samengestelde verba op h. midih-ephàkah : kattekwaad uithalen; spelen, ondeugend zijn; ěban' fah' waroh: zich vermeniguuldigen door kinderen baren; sèk' màtah: doodsteken; sẻf' bòhoh: onredelijk toornen; ik' kalih: gaan-graven; bàgek-toron-elif' lifoh: zeer vast slapen; angak-oeteh: 'n goed nogje hebben op, overspel bedrijven met;

Voorbeelden van samengestelde verba op $\mathrm{k}$.

hòsak-soep' soepak: zeer vroeg opstaan;

sèk' màtak: iets doodsteken; ol'sakik: wederom naar huis gaan (olih: naar huis teruggaan.) sèf' bò hok; onredelijk boos zijn tegen; ik' kalik: gaan-uit of in graven; eprèp' lè dak: valsch spreken, liegen.

nak: bezittelijk voornaamwoord $3^{\circ}$ pers. enkv. zijn, haar voor zaken en personen behalve voor kleedingstukken en deelen van 't lichaam ni, Sap. N. Har. Hil. Asil. nak hoema: zijn huis, haar huis, nak àn a t: zijn, haar kind; nak wali: zijn zwager, nak kòkol: zijn, haar draagmandje; nak wèt a: zijn haar haald.

Inderdaar is echter dit niet met 't Holl. zijn, haar, te vertalen maar met 't in de spreektaal gebruikte z'n, z'n huis, d'r huis; hij ging naar z'n huis, zij ging naar d'r tuin, derhalve zonder den bepaalden nadruk te laten vallen op $\mathrm{z}$ ij $n$ of $\mathrm{haar}$.

Wil men den bepaalden nadruk op zijn, hààr laten vallen, hij ging naar zijn huis, niet naar dat van 'n ander, dan zegt men rin dàikoh gam rinne nak hoema: hij ging naar hij (emphat-vorm van rin: hij), $\mathrm{na}$ : bezitter $+\mathrm{k}$ rudiment van "ke hetgeen bezeten of gebruikt wordt» Kern. Fidji blz. 26. r. 5 v. b. huis.

De bezittelijke voornwdn. zijn:

nang: mijn nang wàga: mijn vaartuig,

nam: uw nam fikoel: uw werptol;

nak: zijn, haar, nak hawa: zijn, haar tuin;

namik ons (excl.) namik was'lale: onze boomgaard;

nan of nanik: ons (incl.) nan, nanik bidoet: ons werpnet. 
sirroea noen: Zij getweeën hun; sir roea noen òpo: hun beider grootvader.

no en: hun, haar; no en e d hà mat: hun, haar visch; nim: uwlieder; nim oepoe: uwlieder overgrootvader.

Voor lichaamsdeelen, gedeelten van boomen, planten, bloemen en kleedingstukken gebruikt men de onder volgende bezittelijk naamwoordelijke achtervoegsels.

ngo: mijn; mo: uw; ne: zijn, haar; nami: onze (excl.); nani: onze (incl.); nimi: uwlieder, uw; no: hun, haar voor dualis en veelvoud.

òlon: hoofd; òlòngo: mijn hoofd. De $\mathrm{n}$ van òlon blijve voorloopig buiten bespreking. Zie bij anorganische $n$.

fàhan: hand, fah a m mo: uw hand. Men lette op den overgang van den anorganen $\mathrm{n}$ van fà $\mathrm{han}$ in $\mathrm{m}$.

làb o en: baadje; làbo enne: zijn, haar baadje ;

fitin: voet, fitinnami: onze (excl.) voeten;

mân: tong, mânnani: onze (incl.) tongen;

if oetin: hoofddoek; if oetinnimi: uwlieder hoofddoeken;

toetoen: bloem, to etoenno: hun, haar bloem, bloemen;

foean: vrucht, foeanne: zijn, haar vrucht, vruchten;

lawan: tak, lawanno: hun tak, takken.

9). fà for: fà fo e: varken, hà ho e. K. T. R. H. W. Kbb. Pi, Sap. N. Har. Hil. Asil. à pal. S. fà for. varkens.

Substantiva eindigend op 'n consonant kunnen zoowel 'n enkelvoud als 'n meervoud beteekenen. Dit moet uit 't zinsverband blijken.

fikoel: werptol, werptollen; sàhin: pagaai, pagaaien, $\mathrm{e} \mathrm{d} \mathrm{h}$ à $\mathrm{m} \mathrm{a} \mathrm{t}$ : visch, visschen ;

Substantiva eindigend op 'n vocaal zijn enkelvoud.

ho ema: huis; fòdo: draagmand; foede: heuvel;

wali: zwager; asoe: hond.

Wil men 'n meervoud aanduiden, dan wordt achter den slotklinker 'n $r$ geplaatst. Bij die substantiva, die in 't enkelvoud eindigen' op ' $n$ oe verandert deze oe tevens in ' $t$ meervoud en wordt 0 .

hoema, hoemar: huizen; fòdo,-fòd or: draagmanden; foede, foeder: heuvels; wali, walir: zwagers; asoe: hond, a sor: honden; fà fo e: varken, fà for: varkens; fàtoe: steen, Dl. 75 . 
fà to r: steenen; Wà En o e: plaatsnaam, Wà Enor: menschen van uit Wà Enoe; kà koe : berg, kà k o r: bergen.

Komen in 'n woord in de opeenvolgende lettergrepen -oe-oe, voor dan veranderen deze beide oe's in o's. moefoe, uitgestorven bijv. één huisgezin, stam; mòfor: uitgestorven meervoud, twee of meer geslachten, huisgezinnen, stammen, enz.

10). ědemen, samengesteld uit $\check{e}+\mathrm{deme}+\mathrm{n}$.

't Prefix è.

De uitspraak dezer e helt naar de $\mathrm{u}$ in $\mathrm{kruk}$, pluk; is bijna gelijk aan de Boegin. ěnjtje, dus niet volkomen gelijk aan de e in geloof, gedragen enz. Zij wordt eeniger mate in de keel en afgebroken uitgesproken. We zouden 't best doen ${ }^{\prime}$ ' te schrijven. Waar de uitspraak nu duidelijk genoeg is schrijven we eenvoudig e.

Dit prefix dient tot de vorming.

a. van den Tegenwoordigen tijd van sommige verba.

Prof. Kern. Fidji enz. blz. 106 zegt; "In 't Mao, kan de Teg. T. - zoo heet het - aangeduid worden door e vóór en tegelijk a n a achter het gezegde te plaatsen. Daar het koppelwoord aan 't Mao. onbekend is, zoo volgt dat e haere vermoedelijk niets anders is dan letterlijk = Engelsch proceeding.

In de L. E. is tjân: hooren, dit is, de benoeming van de volbrachte handeling of 't bevel, hooren! hoor! hoort. ¿tjân: hooren, luisteren, het werkwoord in den tegenwoordigen tijd als handeling à $\mathrm{b}$ à e $\mathrm{t} \mathrm{j}$ ân : ik hoor, ik luister, luisteren aanwezig zijn bij mij.

Łdèngan: gebeuren, geschieden, worden; ědareh: leunen; ědoeëh: geven; ëdedoek: opstapelen; ědaëh: bijna vallen; édoekeh: zich bedroeven; ědohih: vertellen, verhalen; ědòhik: iets aan iemand vertellen, verhalen; ‘bòloh: 'n wond met zalf, pleister bedekken; ¿jah: scheuren; ěnàhoeh: afspreken iets; ¿̌nàg $\mathrm{a} h$ : rondloopen van slecht volk; ěngoeteh: den koes-koes roepen; е̌reih; weigeren; е̌ràmah: waarzeggen.

b. tot 't vormen van substantiva.

eran fakkel, ěeran: bloemkolfscheede van de maïs; lèdah: vergeefsch, ělèdà : søort reiger, die altijd in elkander gedoken zit en zeer moeilijk is te strikken; deoeh: iets in iets anders doen, edeoet: haarwrong; là poeh: iets in iets anders 
wikkelen, ěl à p o e t: vlies; $1 \mathrm{a} \mathrm{b}$ a k: vliegen, e $\mathrm{là} \mathrm{b} \mathrm{a}$ : groene leguaan; boekoe: bult, knobbel, éboekoe: gong; tangih: huilen, weenen; ěnangit: 't huilen, 't weenen, gehuil, geween; kalak: roepen, ěnalat 't roepen, geroep; kah: eten, ěnât: 't eten;

c. tot 't vormen van sommige adjectiva.

ěd o eke: bedroefd; ěbàfan: dom, ěgòsa: lang van duur, ělèken: krom; ěmèngen: nooit te voren gezien, geheel vreemd; ěmàtan: rauw; ěnaboe: bedaard; ěnèga: bepaald, zeker; ěwä t: vochtig (van kleeren) grondwoord wà : water; ěbà li: linker; ěw àn a : rechter; ěd e men : veel.

De anorganische slot $\mathrm{n}$ dient:

a. tot de vorming van de namen van lichaamsdeelen, deelen van boomen, planten, wapens.

òloh: vooroverbuigen; òlon: hoofd; $\mathrm{kàdan}$ : voet; $\mathrm{mân}$ : tong; fòlon: haar; ròhin: bot; moeën: mond, tepel; poesen: navel; la wa n: tak; sàngan: twijg; ò mon: blad; toetoen: bloem; foean: vrucht; $m$ äe $n$ : handvat, gewest ; is in: lerhmet; pèn a n: scheede.

De meeste dezer substantiva zijn van verba afgeleid.

b. verwantschap met spreker;

à $\mathrm{m}$ a: vader; à $\mathrm{m}$ a $\mathrm{n}$ : bij 't aanspreken van vader of 't spreken over vader; in a: moeder; inan: bij 't aanspreken van moeder of 't spreken over haar; mème: oom, schoonvader; m è ne n : als bij vader; jòi: tante, join; òpo: grootvader, ò pon ; (ò pon beteekent naar 't zinsverband ook kleinkind) lò s o : tante, schoonmoeder, lòs on.

Uitzonderingen maken hierop $\mathrm{n}$ à hat: broeder; $\mathrm{n}$ à ha $\mathrm{s}$ : vijand, persoonlijke vijand; fè t a : zuster; à n a t: kind; (à n a n ; kind van 'n zoogdier, fà f' à n a n: varken, kind er van, big.).

c. Samengestelde woorden waarin 't laatste woord der samenstelling 't product is van 't eerste. De anorganische slot $n$ heeft in die woorden de beteekenis van: "er van».

niw'waën: niwe: klapper; wa ën: wà: water + e : het $+n$ : er van, klapper water het er van, klapperwater; niwe-wa ën: klapperolie; ràm a n-waën: oog water het er van, traan; faf'ànan: varken kind er van, big; sos'waën: sòson: borst + wa ën: water het er van, zog; en bàget el en: enbàget: 't liggen, 't slapen, van bàgeh: liggen, slapen, elen: plaats er van, restant er van, van eleh: blijven, 
resteeren, plaats waar men geslapen heeft; Mal. bekas petidoeran; efnòit-elen: efnòit: 't baden, van fòih: baden, plaats waar men gebaad heeft.

d. de vorming van eenige adjectiva:

deme: demen: veel; taoe, taoen: vol; foe, foen: leeg; bònoh, bònon: gaar; ěnosi, ěnosin: oud; nereh: zwetsen, neren: verwaand; sòpah: behagen scheppen in, sòpan: mooi; solah: op den schoot dragen; solan: lief; sòpan-solan: worden steeds in samenstelling gebruikt in de beteekenis van prachtig-mooi; sèfeh: toornen, boos zijn op! sèfen: boos;

e. de vorming van substantiva van verba, die 't middel aanduiden, waarmede de handeling wordt verricht.

sodih: stompen, sodin: gewei; sèkah: steken, sèkan: steekspoel; sàh $\mathrm{ih}$ : pagaaien, $\mathrm{s}$ à $\mathrm{in}$ : pagaai; $1 \mathrm{i}$ ëh: geluid geven, liën: stem; tedeh: geluid geven, teden: geluid, òloh: buigen voorover, òlon: hoofd; $\mathrm{n}$ in oe h: beschaduwen, ninoen: schaduw; soerah: prikken, soeran: voetangel;

f. tot 't vormen van substantiva van verba die' 't product der handeling zijn.

lolih: verzamelen, lolin: verzameling, groep; pòt oh: branden, pòton: hitte; tòhoh: nederdalen, tòhon: paadje, wegje, door 't voortdurend nederdalen langs de helling van den berg gevormd; à he h: ademhalen; à hen: adem;

g. tot 't vormen van den zelfstandig naamwoordelijken werkwoordsvorm met behulp van 'n prefix.

$1^{\circ}$ prefix ě $-\mathrm{n}$;

kèhah: stijgen, ěnèhan: stijgen, lea ěn èhan: (lea: zon) oosten; ngè teh: bijten, èngèten: 't bijten; tewa h: weten, ěnewan: 't weten (men lette op de afwisseling van $t$ en $n$ ) tòhoh: dalen, ěnohon: 't dalen; tàtih: naar beneden zakken, ěn àtin: 't naar beneden zakken; ěn ò h on-ěn àtin: nakomelingschap.

$2^{\circ}$ prefix en $-n$;

lè pah: stijgen, en lè pa n: 't stijgen, stijging; d ó efa h: ontmoeten, endoefan: 't ontmoeten, ontmoeting; hejah: joelen, enhejan: 't joelen, gejoel; màneh: eed zweren, enmanen: 't eed zweren, eed; neweh: leven, ennewen: 't leven, leven; $\mathrm{má}$ tah: sterven, enmàtan: 't sterven, dood.

N.B. Is de aanvangsmedeklinker van 't werkwoord 'n s of 
'n f, dan heeft er bij de voorplaatsing van 't prefix en omzetting der beide medeklinkers $n$ en $s, n$ en $f$ plaats.

s à d e h: antwoorden, es n à d en: 't antwoorden, antwoord ; sibih: helpen, esnibin: 't bevelen, bevel; (enșibin: 't helpen, hulp is 'n uitzondering) silih: ruilen, es nilin: 't ruilen, ruiling; soeboeh: noemen, uitspreken, vloeken iemand; esnoeboen: 't noemen, 't uitspreken, 't vloeken iemand, vloek; s òmoh: vergelden, 'n geschenk; esnomon: 't vergelden van 'n geschenk, vergelding; sogoh: ondergaan, es nògon: 't ondergaan van de zon.

fò toh: snijden, kerven, e f n ò t o n : 't kerven, 't snijden ; foesah: boos ergens op afgaan, ef noesan: 't ergens boos op afgaan; fòkih: inwikkelen, efnòkin; 't inwikkelen, 'n pakje;

$3^{\circ}$ prefix e $m-n$;

$\mathrm{h}$ à $\mathrm{e} h$, e m hà $\mathrm{t} \mathrm{a}$ : rotan van den koes-koesstrik;

hèdeh, emhèden: doel; k à teh, em kà ten: medicijn ;

lò $\mathrm{moh}$, em lòmon: geboorte.

N.B. Lang niet alle verba laten deze vorming op $\mathrm{n}$ genoemd onder $1^{\circ}, 2^{\circ}$ en $3^{\circ}$ toe.

h. prefix per- $n$ voor de vorming van reciproque werkwoorden.

boesoek: aanklagen, p еъоеsоen: elkander aanklagen ; bohik: schelden, beleedigen, pěbohin: elkander schelden, beleedigen (bohih: 'n ander z'n partes prosteriores toedraaien en zich zelf er 'n klap opgeven). dedoeh: volgen, pědedoen: elkander volgen; doefeh: ergens tegen aanloopen; pědoefen: tegen elkander aanloopen; doedah: aanbrullen van varkens; pědoedan: elkander aanbrullen; eftoehah: spuwen, peftoehan: elkander spuwen; es pèleh: smijten, pespèlen: elkander smijten.

N.B. Uit de beide laatste voorbeelden blijkt dat, als 'n werkwoord met 'n e begint deze in de samenstelling behouden blijft en de è van 't prefix wegvalt.

gogih: krabben, efgogih: voortdurend krabben, pefgogin: elkander voortdurend krabben; gaweh: vasthouden, pĕgawen: elkander vasthouden; kà toek: iemand iets zenden, pěkatoen : elkander iets zenden, over en weer geschenken zenden; kèmeh: knijpen, $\mathrm{p}$ ěkèmen: elkander knijpen; 1 à $\mathrm{t} \mathrm{a} \mathrm{h:} \mathrm{hakken,}$ e plà t a h : voortdurend hakken, vechten, $\mathrm{pep}$ l à $\mathrm{ta} \mathrm{n}$ : elkander voortdurend hakken, met elkander vechten met wapenen, 
oorlog voeren; lòmoh: vleien, omhelzen, pělòmon : elkander vleien, elkander omhelzen; e plòmoh: voortdurend vleien, omhelzen; peplòmon: elkander voortdurend vleien, omhelzen; mòloh: onderduiken, pòlok: iemand onderdompelen; pěpòlon: elkander onderdompelen; moesik: medelijden hebben met, pèmoesin: medelijden met elkander hebben; sèkah: steken, pěsèkan: elkander steken; sibih: helpen, pěsibin: elkander helpen (pessékan: elkander voortdurend steken, pessibin: elkander voortdurend helpen.)

N.B. Vele werkwoorden laten deze vorming tot reciproque niet toe. In dit geval.moet de reciproquevorm gemaakt worden door verbum + saro: elkander.

i. door 't prefix em $+\mathrm{sia}$ : deel $+\mathrm{n}$ : er van, emsian: één met den nadruk, zijnde 'n enkel exemplaar er van; hoema emsian: huis zijnde 'n enkel exemplaar er van, één huis; enhero engaoet emsian: lans' vasthoudsel zijnde een exemplaar er van; één lans.

Lalen ${ }^{11}$ ) sà Toean-Ko-Làtoe di ${ }^{12}$ ) dàsioek ${ }^{13}$ nak keer 'n meneer-de-Vorst die zond z'n

Eens zond die "Meneer-de-Vorst» z'n veertig slaven zeggende. à $\mathrm{ar}^{\mathbf{1 4}^{4}}$ ) $\mathrm{polpa}{ }^{15}$ ) fène $\mathrm{h}:{ }^{16}$ ).

slaven veertig zeggende:

11). lalen: lale: binnenst, la le $+\mathrm{n}$ : binnenste er van, psychologisch hart; keer; màal; la len sà: 'n keer, eens; la i Sap. lawai. N. waini, laini Har. laine Asil. Hil. naïn K. T. H. W. nea. Pi. nawa K. T. H. W. lawa. R. Kbb. lakwa S. één keer, één maal, twee keer, drie maal enz. lalen-emsian; lalen roea; lalen tèlo; lalen pa; lalen lima; lalen ne; lalen pito; lalen etroea; lalen etjia; lalen pòlo. Zonder dat evenwel genoemd wordt wat één, twee, drie, enz. maal genomen wordt.

Lalen pila sir doesobak haïk gam foek' Ambon? Keeren hoeveel zij zeilden reeds naar land' Ambon? Lalen pito: keeren zeven.

Bij vermenigvuldiging wordt dit lalen ook gebruikt:

$$
\begin{aligned}
& \ldots \times 1: \text { lalen emsian of } 1 \text { alen sà; } \\
& \ldots \times 12: \ldots \text { lal' roeak; } \\
& \ldots \ldots \times 3: \ldots \text { lal' tèloet; }
\end{aligned}
$$




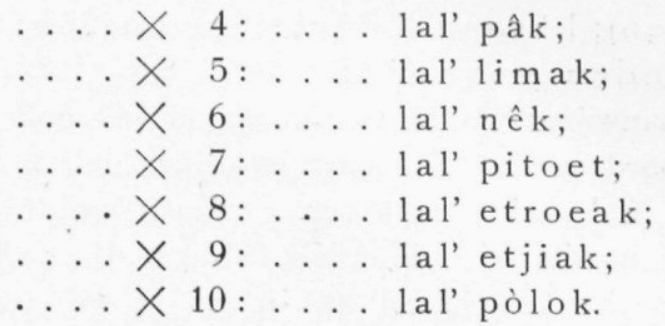

$3 \times 7=$ tèlo lal' pitoet verkorting van tèlo etah lalen pitoet: drie tot zeven keeren. Hieruit blijkt tevens, dat de gedachtengang anders is dan bij ons. Bij ons toch is $3 \times 7=$ $7+7+7$, bij den Boeroenees is $3 \times 7=3+3+3+3+$ $3+3+3$; drie tot zeven malen toe.

12). Toean-Ko-Là toe di.

$\mathrm{di}$, aanwijzend voornaamwoord die, dat, enkelvoud, die, meervoud.

De aanwijzende voornaamwoorden zijn :

na: deze, dit, enkelv.; deze, meerv.,

di: die, dat, enkelv.; die, meerv.,

à k i: letterlijk gind s, daar.

Oorspronkelijk zijn deze woorden volgens ons taaleigen bijwoorden van plaats, inderdaad zijn ze echter beter te beschouwen als bijvoegelijke naamwoorden van plaats; $n a$ : hier, op de plaats van spreker; hoema na: huis hier, hiersche huis, dit huis, hier waar spreker zich bevindt.

di: daar, op de plaats niet bij spreker; hoema di: huis daar, daarsche huis, dat huis;

à $\mathrm{ki}$ : ginds, niet bij spreker noch aangesprokene, maar verder weg; ho e ma à ki : gindsche huis.

Dat $\mathrm{na}$, di en àki bijwoorden van plaats geworden zijn blijkt ook uit fina: fi: te $+\mathrm{na}$ : hier, te hier, alhier, hier; fide: te daar, aldaar, daar; fiàki: te ginds, ginds; (Prof. van Ophuysen Mal. Gram. $1^{\mathrm{e}}$ Druk $\S 62^{\mathrm{a}} \mathrm{iki}$, ikoe, ikå) De woorden $\mathrm{na}$, di en àki laten in de L. E. geen pluraalvorm toe.

Wanneer wij in 't Nederl. den nadruk leggen op 't aanw. voornw. dit huis, diè boom, dan doet de Boeroeman dit, door 't aanwijzend voornw. te laten volgen door den $\mathrm{n}$ adruksa a nwijz er e.

dit huis: hoema na e, dàt huis: hoema di e; die 
brug (bruggen): kà soedal di e; dèze huizen: hoemar na e; die honden: asor di e.

De nadruksaanwijzer wordt achter $\mathrm{na}$ en $\mathrm{di}$ ook gebezigd, wanneer 't woord waarop 't aanw. voornw. betrekking heeft door ons in 't Nederl. in den accus. geplaatst wordt.

hij kocht dàt baadje: rin dàsàfeh làboen di e; zij verloren dèze pagaaien: sir doedifoek sàhin na e; gij moet dèzen steen uitgraven: pàtehen oek dàbàkalîk fàtoe tinan na e.

$\mathrm{Na}$ àki: gindsche, gebruikt men in den emphat: vorm en bij den accusatief di en bij zeer sterken nadruk in beide gevallen di e.

gindsche berg: kàkoe àki; die gindsche berg: kàkoe àki di; diè gindsche berg, dièn gindschen berg: kàkoe àki dì e; fi saka kàkor fòfon àki di e: te op bergen toppen gindsche dié: op gindsche bergtoppen; en dus niet ergens elders.

Op vragen als: "welk huis bewoont gij?" kunnen wij antwoorden dit, dàt, gindsche; in de L. E. kan men dergelijke vragen eveneens beantwoorden met, na e: dit; di e: dàt, àki di e: gindsche.

Ook kan men op: "welk huis bewoont gij?» antwoorden: ihà na e: is hier, ihà di e: is dat; in 't meervoud ihar na e: zijn hier, ihar di e: zijn daar, ihà: is, ihar: zijn àki di e: is, zijn ginds.

'n Andere wijze is die met met tà: is, zijn, is aanwezig, zijn aanwezig. na tà, di tà, 't welk 'n verkorting is van fi na tà: te hier is, zijn; te hier is, zijn aanwezig; fi di tà: te daar is, zijn; te daar is, zijn aanwezig; vandaar deze, dit, met nadruk, die, dat met nadruk, oek dàbàdèfoek hoema tenik ke: gij bewoont huis welk het?, welk huis bewoont gij? hoema nà ta: huis hier is, dit huis; hoema di ta: huis daar is, dàt huis.

Eigenlijk geeft 't ' $n$ antwoord op de vraag waar is het huis dat gij bewoont? bijv.: nam elet-endèfoet tà fi do? Uw verblijfplaats is te waar? Waar is $U w$ verblijfplaats? tà fi na: is te hier; is hier; tà fi di: is te daar, is daar, tà fi àki: is te ginds, is ginds.

Op de vraag wèlk mes? met den nadruk op wèlk, antwoordt men nà ta! di ta! bij spreker zijnde, niet bij spreker zijnde, vandaar dit is ('t); dat is ('t); dit: met nadruk; dàt: met nadruk, waarbij de gedachte aan elkander mes uitgesloten is.

Van 't plaats-aanwijzende woord na, wordt 't tijd-aanwijzende: nu gevormd, naběna: nu, uit na + bě + na. 
Op dezelfde wijze vormt men van di 't aanwijzend (demonstratieve) vnw. zelfde: dibědi; dezelfde: dibęih he.

wat is dit?: sàpan na? sà pa: wat $+n$ : er van $+n a$; wat is dat? sàpan di? sà pa: wat $+\mathrm{n}$ : er van $+\mathrm{di}$.

13). dàsioek: sioek: zenden, sturen iemand; dàsioek: zond.

14). à ta $\mathrm{r}$ : pluralis van àt a: slaaf (Sap. N. Har. Hil. Asil. K. T. R. W. Kbb. Pi. S.) In de Boeroemaatschappij behooren geen slaven thuis. Werd in vroeger dagen bij 'n gevecht 'n mensch gevangen genomen, dan werd de gevangene in den stam, die overwinnaar was ingelijfd en tot 'n mensch van dien stam gemaakt, kreeg den geslachtsnaam dier stamgenooten en deelde in hunne rechten wat 't bewonen en betuinen van den stamgrond betreft. Zoo'n mensch noemde men dan ànat bàlih ta o en: àn at: kind, bàlih: veranderen, taoen: taoe: mensch $+\mathrm{n}$ : er van; de geroofde was dus door de opname in den nieuwen stam, 'n veranderd, 'n nieuw mensch geworden.

In den tegenwoordigen tijd heeft nog menigmaal adoptie plaats, inzonderheid adopteert met algemeen goedvinden 'n familie, en hierbij heeft dan 't zelfde plaats. Zoo'n geadopteerde staat dan ook bekend als 'n à n a t-bàlih-taoen.

15): pol'pa: samengesteld uit pòlo: tien + pa: vier. 't Is inderdaad 'n verkorting van pòlo etah lalen pa: tien tot keeren er van vier; tien tot vier keer. hoetoe haa: Sap. Har, hoeoe haa N. hoetoe ata: Hil. Asil.

pol'roea: twintig; pol'tèlo: dertig; pol'lima: vijftig; pol'ne: zestig; pol'pito: zeventig; pol'etroea: tachtig; pol'etjia: negentig.

In deze telwoorden wordt dus ook de regel gevolgd, dat 't bepalende woord volgt op het bepaalde.

16). fèneh: zeggende; wel te onderscheiden van 't voegwoord fène: dat.

Hij vertelde, dat de koning dood was: rin dà ědòhik, fene lèber re dàmàtah haîk; ik zie dat de zon ondergaat: à bàkitah fène alam dàbàmò $l o h$.

kim ${ }^{17}$ ) ik' kalak ${ }^{18}$ ) Kalampo ${ }^{19}$ ) $1 a^{20}$ ) rin gijlieden gaan roepen Kalampo dat hij gij gaat Kàlampo roepen dat hij deze mijn varkens fokke. dà bàboah nang fàfor na e
opvoeden mijn varkens deze 
17). kim: persnl. vrnw. $2^{\circ}$ pers. mrvd. bij de vervoeging van de werkwoorden; ook bij de gebiedende wijs in zachteren vorm kim ikoh: gij lieden gaat? kimi ikoh: gij lieden (en geen anderen) gaat; i mi Sa p. N. Har. Hil. Asil, K. T. R. H. W. Kbb. Pi. S.

18). ik' kalak: samengesteld uit ikoh: gaan † kalak: roepen, ik'kalak: gaan roepen, één accenteenheid.

De L. E. is zeer rijk aan samengestelde woorden, die gevormd worden door samenvoeging van verschillende woorden. Evenals in 't Hollandsch bij samenstelling van sommige woorden 't laatste lid van 't eerste woord dat de samenstelling vormt wordt weggeworpen, bijv. geschiedschrijver, voor geschiedenisschrijver; schermaaiën, voor schermen maaièn, geschiedt dit in de L. E. met een of meerdere leden der samenstellende woorden.

sèk' matah: sèkah: steken + màt a h: (màt a: dood, door achtervoeging van de $\mathrm{h}$ tot 'n werkwoord gemaakt); sèk' $\mathrm{m}$ à $\mathrm{t} \mathrm{a}$ h: doodsteken; steek, steekt dood; sèk' màtak: iemand, iets doodsteken; steekt, steekt (hem, haar; het, iets) dood!; $\mathrm{h} \mathrm{a} \mathrm{m}$ ' betah: hà m a h : zoeken; b e t a h : kunnen, krijgen, raken, treffen, ham' beta h: vinden, (iets waarnaar men gezocht heeft); ěban' fah' wa roh: èbàn a k: kinderen baren, fàheh: toevoegen; waroh: vermeerderen, ěban' fah' waroh: veel kinderen baren, zich vermenigvuldigen door geboorte; hoem' kolon; hoema: huis, kòloh: ergens onder zijn, zich ergens onder bevinden; kòlon: kòln $+\mathrm{n}$ : ruimte onder + er van, ruimte-er-onder; ho em' kòlon: voorraadschuur — 'n huis op palen met 'n ruimte er onder; niet te verwarren met hoema kòlon: ruimte onder 'n huis, bijv. 'n huis op palen gebouwd. hoem' damoen; hoema: huis, damoen: schat, hoem' d a moen: schathuis; fet'àga; fèten: gierst, àga: zaad, fet'à g a: gierstzaad; g a m' fa f' feak; gamna: gelijk, fàfoe: varken, feak: zich plotseling opheffen; letterlijk gam' faf' feak: gelijk 'n varken zich plotseling opheft v. d, opschrikken, ontstellen; lof' nêt: lofin: kant, zijde, $(1 \circ \mathrm{fi}+\mathrm{n})$; ne: zes $+\mathrm{t}$, achtervoegvoegsel tot 't vormen van adjectiva: lof'nêt: zeskantig, zeszijdig; ra m' pôt: rà man: oog, pôh: groot, wijd open zetten, $t$ : vorming adject: ram'pôt: koloogig.

Bij plaatsnamen heeft deze samenstelling met afkortingen, bijna altijd plaats. 
Nam' role: nama: baai, role (ook em role) 'n soort visch. Nam' role: de Role-baai, de baai waarin veel role voorkomt; Nam' Tifoe: nama: baai, tifoe: vijver, vijverbaai; Lek' soelah: lekoen, bocht, soelah: formeeren, geformeerde bocht.

(Tot deze bocht staat 't verhaal van den Hèm' waroet: (Hendriks' legende VI) in betrekking).

Mngès' Waën: e mngèsa: vlakte waën: water er van ; watervlakte; En' biloro: ena: zand, biloro: stam naam, Biloro zand; W à sa ng' bélen: W à: water, rivier, sàngan : takje, spruit; bèleh: tegenhouden, tegenhoudend zijriviertje ; foek' Ambon: foeka: land, Ambon: Ambon, en niet 't land Ambon, dit zou zijn foeka Ambon.

19). Kà Lam po e.

e. is in de L. E.

$1^{\circ}$ nadruksaanwijzer.

$2^{\circ}$ 't bepalend lidwoord voor 't enkelvoud.

$3^{\circ}$ persoonlijk vrnw. $3^{\mathrm{e}}$ pers. enkelv. $4^{\mathrm{e}}$ naamval.

e als nadruksaanwijzer.

Is in 't Mak: a en in 't Boeg. e oorspronkelijk niet anders dan 'n nadruksaanwijzer geweest, later zijn ze bepalende lidwoorden geworden (Matthes. Mak-Gram. § 60. Boeg. Gram. § 174) de L. E. heeft den nadruksaanwijzer e voor 't enkelvoud en 't meervoud in alle zuiverheid bewaard.

Vraagt men om 't een of ander voorwerp of naar 'n persoon zonder op die zaak of dien persoon den bijzonderen nadruk te leggen, dan gebruikt men 't zelfst. nw. of den naam zonder eenige bijvoeging.

Wàg a : prauw! kĕtànen : mes! àman : vader! (van spreker); inan: moeder (van spreker). Fidir: Fidir! mannen naam.

Wenscht men den bijzonderen nadruk te leggen op 't bedoelde voorwerp of den bedoelden persoon, dan gebruikt men den nadruksaanwijzer e.

wàga e! prauw!! we zouden kunnen roepen prauwé. kèt ànen e! mes!! mesé; a man e !: vadèr!! in a n e!: moedèr; Fidir e! Fidìr!! Mite! Mite e!! Bòrok! Bò rok e!! Ja n! Ja n e!! enz.

't Bepalend lidwoord voor 't enkelvoud is e.

Gaat een woord uit op 'h klinker dan wordt 't bepld. lidwoord e eenvoudig op zich zelf staande achter dat woord geplaatst, zoo goed als in. 't Nedrl. 't daar vóór 'n plaats vindt. Sluit 'n 
woord echter met 'n medeklinker, dan wordt deze zelfde medeklinker de opener van 't bepalend lidwoord.

De voorbeelden zullen dit duidelijk maken:

to e bà : handtrom, to e b a e : de handtrom ;

àn $\mathrm{a}$ : witte mier, àn a e: de witte mier;

ipa: kenari, ipa e: de kenari;

fà to e: steen, fà to e e: de steen;

as oe: hond, a soe e: de hond;

betoe: convocatie (blad met knoopen er in gelegd);

betoe e: de convocatie;

òë: krabbe, ò ë e: de krabbe;

bose: peulvrucht, bose e: de peulvrucht;

fò do: draagmand, fòdo e : de draagmand;

tòdo: kapmes, tòdo e: het kapmes;

wali: zwager, wali e: de zwager;

pàh $\mathrm{i}$ : rogge, pàhi e: de rogge ;

moeën: mond, tepel; moeën ne: de mond, de tepel;

oban: roeibank, oban ne: de roeibank;

toetoen: bloem, toetoen ne: de bloem;

gà b o e $\mathrm{s}$ : kapok, gàboes se: de kapok;

goegoer: tijding, goegoer re: de tijding;

liwit: roer, liwit te: het roer;

sît: zee-egel, sît te: de zee-egel;

tepoet: kip, tepoet te: de kip;

s àge 1: ingewandsworm, sàge $1 \mathrm{le}$ : de ingewandsworm;

fikoel: werptol, fikoel le: de werptol.

Wordt een zlfst. nw. nader bepaald door 'n adjectief dan staat 't bepal. ldw. achter dit adjectief, 't welk tevens als bepaling

't bepaalde woord volgt.

wàg a hât: prauw groot, ('n) groote prauw, wàg a hât te: prauw groot de, de groote prauw; fikoel fehoet: werptol nieuw, ('n) nieuwe werptol; fikoel fehoet te: de nieuwe werptol; fòdo foen: leege draagmand, fòdo foen ne: de leege draagmand: $f a ̀ h$ a n e bà $1 \mathrm{i}$ : hand linker, linkerhand, fàhan ébàli e: de linkerhand; toekeh oeteh kàno bidoet egjak ke: geef aan mij werpnet gescheurd het, geef mij het gescheurde werpnet.

't Bepalend lidwoord voor 't meervoud is o. Staat dit lidwoord achter ' $n$ woord dat eindigt op ' $n$ ' klinker in 't enkelvoud en dus in 't meervoud ' $n \mathrm{r}$ tot sluiter ontvangt, dan opent 't bepal. lidw. meervoud met dien zelfden sluiter $r$. 
wàg a: prauw, wàg a r: prauwen, wàg a r ro: de prauwen ; wali: zwager, walir: zwagers, walir ro: de zwagers; bose: peulvrucht, boser: peulvruchten, boser ro: de peulvruchten; a soe: hond, a s or: honden, a sor ro: de honden; fà foe: varken, fà for: varkens, fà for ro: de varkens.

Men herinnere zich wat boven gezegd is over die woorden welke in 't enkelvoud op o e eindigen.

Wat boven gezegd is omtrent 't bepalnd. ldw. enkelv. wanneer 't achter adjectiva geplaatst wordt, geldt evenzeer voor 't bepl. ldw. plur. Voorbeelden zullen dit toelichten.

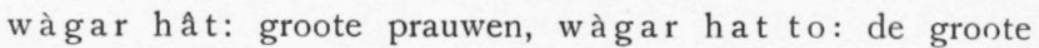
prauwen; fòdor foen: ledige draagmanden, fòdor foen no: de ledige draagmanden; boeèter ta oen: gevulde kisten, boeèter taoen no: de gevulde kisten; fikoel fehoet: nieuwe werptol, werptollen, fikoel fehoet to: de nieuwe werptollen; $\mathrm{k}$ à s o e ma $\mathrm{l}$ g i w e t: harde wig, wiggen, k à s o e ma 1 giwet to: de harde wiggen: e ptà $\mathrm{nak} g \mathrm{am}$ ahe $\mathrm{k}$ bidoet e gjâk ko: breng, naar hierheen, werpnet(ten), gescheurd, de plur., breng de gescheurde werpnetten hier.

Wordt 'n zelfst. nw. gevolgd door 'n soort aanwijzer, dan volgt 't beplnd. lidw. dien soortaanwijzer.

Is die soortaanwijzer ' $n$ pluraris, dan sluit 't beplnd. lidw. meervoud ten overvloede nog met 'n $r$ zooals deze voorkomt achter die woorden welke in 't enkelvoud op 'n vocaal eindigen.

Là Bego dàbà sàfeh kàtin eflòlot emsian:

La Bego koopt mat oprolsel zijnde een er van:

Là Bego koopt één mat; Là $\mathrm{Bego} d$ à bà $\mathrm{s}$ à $\mathrm{feh} \mathrm{k}$ à $\mathrm{t}$ in eflòlot emsian ne: Là Bego koopt de eene mat; La Bego $\mathrm{d}$ à $\mathrm{b}$ à $\mathrm{s}$ à $\mathrm{eh}$ kàt in eflòlot tèlo: Là Bego koop matten oprolsels drie. L. B. koopt drie matten; Là $\mathrm{Beg} o \mathrm{~d}$ à bà $\mathrm{s}$ à feh $\mathrm{k}$ à in eflòlot tor tèlo: L. B. koopt matten oprolsels de drie, L. B. koopt de drie matten; repoeh fàtor tinan nor pòlo: raap op, steenen, brokken, de, tien; raap de tien steenen op.

Zelfs wanneer 't aanwijzend voornw. volgt, blijft 't bepld. lidwoord meervoud gehandhaafd, ook dan wanneer de nadruksaanwijzer e den zin sluit.

repoeh fàtor tinan nor pòlo na; raap deze tien steenen op; repoeh fàtor tinan nor pòlo na e: raap dèze tien steenen op; repoeh fàtor tinan nor pòlo di: raap die 
tien steenen op; repoeh fàtor tinan nor pòlo àki di e: raap gindsche tien steenen op.

rin dàlàtah fikoel lor pa: hij raakte werptollen de vier, hij raakte de vier werptollen: wètar kopin nor ràran: naalden oogen de duizend, de duizend naalden; sir roea doekah-sépoh-miti-mitih pawer foean nor poltemsia: zij getweeën atan totaal op mangga's vruchten de elf; zij getweeën aten de elf mangga's totaal op.

In zijn "Iets over de vijf voornaamste dialecten der Ambonsche landtaal (Bahasa tanah), Bijdr. K. I. 4, I, zegt de schrijver G. W. W. C. Baron van Hoëvell bl. 16, r. 7 v. o.

* Het getal der zelfstandige naamwoorden wordt in den regel niet aangeduid en moet uit 't verband blijken. Er bestaat evenwel, 't geen in weinig talen van den Indischen Archipel het geval is, in de bahasa tanah een bepaalde pluralisvorm.

1). In 't Alfoersch van Boeroe bestaat volgens den heer Wilken ook een pluralisvorm met ro bijv. nitoe, nitoero).

In de dialecten van Saparoea en Noesala oet wordt deze uitgedrukt door o in die van Haroekoe, Asiloeloe en Hila door a achter 't substantief te voegen.

Saparoea en Noesalaoet.

Singularis Pluralis.

Latoel of Laoel.

(koning).... latoe o of laoe o. loemal (huis)..... loema o. potoel (dag) ..... potoe o. ana (kind)..... ana 0 .
Haroekoe, Asiloeloe, Hila.

Singularis Pluralis. latoe .... latoe a. loema. . . loema a. petoe (Asil: Hil:) of potoe (Har.) petoe a of potoe a; ana ...... anna a.

Wij merken op dat, waar in 't dialect van Saparoea 't Substantief in 't enkelvoud op eene 1 eindigt, deze letter in den pluralisvorm wegvalt. De substantiva in 't dialect van Saparoea, die in den singularis op nno en 11 o eindigen, werpen in den pluralis eene $\mathrm{n}$ of 1 weg en eindigen dus op no en lo, wat dan niet, zooals in 't enkelvoud kort maar eenigzins lang wordt uitgesproken: la lánno (sing.) weg, la lanō (Plur.); aroenno (kain) aroenō (Plur). In de dialecten van Haroekoe, Asiloeloe en $\mathrm{Hila}$ verandert dit no en ne in na; lalano (Sing:) lalana (Plur:) la lane (Sing: Hil: en Asil) la lana (Plur).

De noot ${ }^{1}$ van den heer van Hoëvell omtrent 't Alfoersch van Boeroe door den heer Wilken medegedeeld is door wat ' $k$ 
omtrent den pluralisvorm der substantiva en de beide bepld. lidwoorden zei naar ' $\mathrm{k}$ hoop voldoende toegelicht en verklaard.

In de dialecten van Saparoea en Noesalaoet is 't bepalend lidwoord enkelvoud o, welke o als volkomen doch kort wordt uitgesproken. 't Bepalend lidwoord meervoud is ō, 't welk als volkomen o doch lang gerekt wordt uitgesproken, terwijl tevens bij vele woorden de klemtoon verlegd wordt.

Tevens dient opgemerkt te worden dat in 't dialect van Haroekoe 't bepalend lidwoord enkelvoud niet altijd o is, doch meermalen e. aarde: oeme: de aarde oeme e; boom: ainel, de boom: ainel le; prijs: herin, de prijs herin ne; restant: lesin, het restant lesin ne; civetkat; tingaloen, de civetkat: tingaloen ne; hoofddoek: lahatal; de hoofddoek: lahatal le; doorn: roerin, de doorn: roerin ne; inhoud, vleesch: isin, de inhoud, het vleesch: isin ne enz.

Inzake 't beplnd. lidwrd. enkelvoud schikt zich 't Haroekoe dialect voor zoover 't o betreft, naar de dialecten van Saparoea en Noesalaoet, terwijl 't waar dit lidwd. e is, 't overeenstemt met 't zelfde lidwoord en de dialecten van Asiloeloe en Hila en de Liet-Emlia van Boeroe.

In de dialecten van Haroekoe, Asiloeloe en Hila is 't bepalend lidwoord meervoud a.

Op de verdere bijzonderheden, die inzake de bepalende lidwoorden in de Ambonsche dialecten aanleidingen tot bespreking geven, wordt hier niet ingegaan.

20). 1 à rin dà bà boah :

1 à : heeft in de L. E. verschillende beteekenissen.

a. 't doet dienst als nadruks of betrekkingsaanwijzer, dien wij in

't Holl. niet vertallen, terwijl we 't woord waarbij 't woordje 1 à behoort met den accusatief vertalen.

$\mathrm{r}$ in dà bàka la k kà : hij roept je; là jàko ? ten opzichte van ik (dubbel emphatische vorm) mij? rèsek ke là käë: inderdaad het ten opzichte van gij (emphatische vorm) inderdaad, u ! si r d oehàmah san ne ? zij zochten wien het? wien zochten zij? là rin ne: ten opzichte van hij (Emph. vorm v. rin) hèm; là sir ra, sir doebàdèf' bâk: ten opzichte van hen, zij blijven hier; zij blijven hier; wat hen aangaat, zij blijven hier; à $\mathrm{man} \mathrm{d}$ a ěnikah la Mite e : vader (van spreker) vroeg Mite en geen ander; lèber re 
$\mathrm{d}$ à $\mathrm{b}$ à $\mathrm{imah}$ la e mrimo e : de vorst berispt den dorpsbode en niemand anders. Valt de nadruk niet op Mite en dorpsbode dan zegt men: àman daenikah làhah Mite e: vader vroeg (làhah: verzoeken) aan Mite; lèber re dàbàsimah ěngeïh e mrimo e: de vorst berispt (̌ ng ë̈h: in de richting gaan van iemand of iets) den dorpsbode. Jòïn dà èdoeëh s e pkòko walan emsian là Enja Lakir re: Tante gaf ring draad zijnde een er van Enja-Lakir, tante gaf Enja Làkir een ring, dus aan niemand anders. Jòi in dà èd o ë̈h sepkòko walan emsian oeteh Enja Làkir re: Tante gaf een ring (oeteh: ten bate, voordeele van) aan Enja Làkir.

b. là: dat, in de toekomst, in beteekenis gelijk aan zullen, zullende, meestal in 't Holl. te vertalen met o m. rin dàbà ikoh 1 à $\mathrm{d}$ à $\mathrm{s}$ à $\mathrm{e} h \mathrm{e} \mathrm{d}$ hà $\mathrm{m}$ a $\mathrm{t}$ : hij. zij, gaat om koopen visch; zij, hij gaat om visch te koopen; sir doebàeptànak enòi là doeèkfilik ke: zij brengen damar om te verkoopen; letterlijk staat er: hij gaat dat hij koopt visch, zij brengen damar dat zij verkoopen het. De werkwoorden dàsàfeh en doeèkfilik zouden in den praesens-vorm moeten luiden dà bàsáfeh, $\mathrm{d}$ o e bà e kfilik: maar aangezien là reeds den tegenwoordigen tijd aangeeft, behoeft 't niet en doet men 't ook niet.

In den verleden tijd gebruikt men in stede van là, pà. sir doekadoek pà doesàfeh pàla: zij kwamen om zij kochten rijst, zij kwamen om rijst te koopen; rin dà là ta h $\mathrm{k}$ a o e pà dà gà roeh wà g a sà : hij hakte hout om 'n prauw te maken, ltrl.: hij hakte hout om hij maakte 'n prauw.

Zegt men: "hij gaat visch koopen", dan zegt men dit in de L. E. met 't samengestelde werkwd: gaan-koopen, rin dàbaik'sàfeh edhàmat; zij kwamen rijst koopen: sir doedat'sàfeh pà la : zij kwamen-aan- (dàteh: komen aan, komen tot aan, bereiken) koopen rijst.

i k's à feh, d a t'sà feh, ka d o e k - s à feh

zijn woorden vast één accenteenheid

c. $1 \mathrm{a}$ rin dà bàbo $\mathrm{a} h$ : tot de vorming van de voorwaardelijke wijs, te vertalen met dat of zullen dat hij fokke, zullende hij fokken; bobàto e dàsioek kàno là à bàkalak kà: het hoofd zond mij dat $\mathrm{ik}$ u roepe.

d. bij tijdsbepalingen

là beto: van nacht, là beton: gisteren, là beton na e : van daag; là betoe: toen, (betoe: 'n palmblad waarin 
knoopen gelegd worden, naar 't aantal dagen waarop 't een of ander feit plaats zal hebben, 'n convocatie-biljet) là betoen: ten tijde van;

e. Evenals la in 't Boeg. bijv. voor namen gebezigd wordt, geschiedt dit ook in de L. E. maar hierin speciaal voor namen van mannen. Deze namen hebben hun ontstaan dan meestal te danken aan de een of andere omstandigheid of hoedanigheid waardoor de jonggeborene zich onderscheidde. 't Is dus 'n woord om in 't bijzonder den nadruk te leggen op 't volgende, doch mag niet met 't bepalend lidw. gelijk gesteld worden.

Tewah: weten, La Tewah; bose: peulvrucht, La Bose; Mani: Là Mani.

Voor de namen van vrouwen en meisjes gebruikt men enja: waarvan mij de beteekenis tot heden nog niet duidelijk is, overigens gebruikt men 'mhoeka, en bai: die beide maagd beteekenen. Deze twee laatste worden uitsluitend voor gehuwde vrouwen gebezigd.

Bèko ${ }^{21}$ ) nak àtar pol'pa doeikoh pà doekalak Hierop zijn slaven veertig gingen dat riepen Kà L a m po e.

Ka Lampo.

21). bè ko : hierop, hierna;

Hierop gingen zijn veertig slaven om Kà Lampo te roepen. Ka Lampo dà ênikah fèneh: wàhang ${ }^{22}$ ) sápan ne ${ }^{23}$ ) Kà Lampo vroeg zeggende: reden ervan wat het

kim doebàkalak kàno? ${ }^{24}$ )

gij lieden roepen mij?

22). wà h a ng: reden, oorzaak.

23). sà pan ne :

sà pan : samengesteld uit $\mathrm{s}$ à $+\mathrm{pà}+\mathrm{n}$.

$\mathrm{s}$ à : 'n, een ;

pà : is 'n woord om 'n vraag aan te duiden en dit in verbinding met di : daar; pà : heeft dus de beteekenis in dit verband van $\mathrm{te}$ in den vragenden toon: $\mathrm{pà} \mathrm{di}$ : te? daar, daar? Hierop antwoordt men tà di: aanwezig zijn, is daar, te daar, daar!

Dit tà in tà di ? daar? staat naast bà in bà na ? 't welk beteekent aanwezig zijn, is? hier, hier? in den vragenden toon, waarop geantwoord wordt bà n a : zijn, is hier, maar dit in den bevestigenden toon.

Dl. 75. 
sà pa: letterlijk 'n? sapan: 'n + ? + ervan: wat? sà pan ne: 'n wat ervan het; wàh a ng sà pan n e : reden, oorzaak 'n wat er van het, wat (is) de reden er van, waarom?

sà p a n: wat?

sà pan ne: wat het; wat is het? sà pan na: wat dit, wat is dit?, sà pan di: wat dat, wat is dat?

hoema sàpan di? wat voor 'n huis is dat? gèbah sàpan di: wat voor 'n mensch is dat?

kim doebàkalak kàno. ${ }^{24}$ )

24). kàno: accusatiefvorm van 't persnl. vrnw. $1^{\circ}$ pers. enkelv.

't Persnl. voornw. $1^{\circ}$ pers. enkelvoud is à. Dit wordt alléén gebruikt bij de vervoeging van de werkwoorden.

à bàkalak: ik roep; à kalak: ik riep; là à bàkalak: dat $\mathrm{ik}$ roepe; lá à bàkalak sàlak: ik zal roepen; là à bàkalak sal'sàlak: ik zou roepen; à bàmòtih kàno:-ik koude koorts mij; ik heb koude koorts; à bàmàkàsah kàno: ik dorst mij; ik heb dorst, enz.

't Aanwijzend persoonl. voornaamw. van den $1^{\circ}$ pers. enkelvoud is jàko: ik. Dit is niet anders dan de dubbel emphatische vorm van à.

De emphatische vorm van à moet zijn à ko: (Kern. Fidji enz. blz. 20). Aangezien ko niet vóór à kan staan, evenmin als 't lidwoord in de L. E., 't Makas; Boeg, en de Ambonsche talen, staat ko dus achter à. Maar à ko is als zoodanig niet in gebruik wel $\mathrm{jàko}$, 't welk niet anders is dan de verkorting van $\mathrm{i}(\mathrm{j})$ à $\mathrm{ko}$.

Deze $\mathrm{i}$ is de persoons of zakenaanduider waarover Prof. Kern spreekt in zijn Fidji enz. blz. 29.

Deze i komt in de Boeroetaal voor.

$1^{\circ}$ in beleefdheidstermen bij 't aanspreken van personen om aan te duiden, dat hij de een of andere eigenschap in bijzondere mate bezit. Kä̈ i ha: gij de groote; kaë i ěràsa: gij de machtige, kae i ěwasa: gij de rijke; ò po gèb' i ha: God mensch de groote, Groote God; bij 't aanspreken van God; $2^{\circ} \mathrm{i}$ : in de beteekenis van dinges (anoe) wanneer men niet zoo gauw op den naam van den persoon of de zaak kan komen dien men in z'n gesprek noodig heeft.

Van dit i: dinges, is gevormd 't act: werkw: ih: dingessen. 
O e k dà bà po ena h sà pa n n e ? gij doet wat het; wat doet gij? à bàih: ik dinges. verder 't a ct. transit. werkw. ik: dingessen. Iemand is bezig z'n prauw te breeuwen en men vraagt hem: "wat doet gij?» en hij kan niet op 't woord toepik: breeuwen act. trans. iets breeuwen komen, dan zal hij antwoorden à bài $\mathrm{k} \mathrm{n}$ ang wàg a: ik dinges m'n prauw. $3^{\circ}$ i: zaak, geval. (perkara, hal.)

Van iemands zaak sprekend vraagt men oek dà jân haik i di e? hadt gij die zaak, dat geval reeds gehoord? sir doe bà e psi' sa r' la lek i na e: zij overleggen gezamenlijk deze zaak, dit geval;

Van dit $i$ is door achtervoeging van e 't substantief $i$ ë gevormd 't welk ding, goed, wa a r beteekent. ië sà pan $\mathrm{na}$ : wat voor 'n ding, wat voor goed, wat voor waar is dit? ië-е̌nan: goed, waar om te eten, eten, spijs; de hoofdschotel ;

i ë-emtaët: ding, scherp, wapen, i ër-emta ët: dingen scherpe, wapenen; ië-ekneïn: goed, waar, ding, bewaard, erfstuk.

Dat jàko: niet anders is, dan 'n verkorting van ijàko wordt bevestigd door 't bezittelijk voornw. $1^{\mathrm{e}}$ pers. enkelv. in den emphatischen vorm. míjn, van mij en van niemand anders. ija nang: míjn; letterlijk ik bezitter ervan.

Sanne nak àma e dapéf' màtak fàfoe na e: wie het bezitter ervan vader de schootdood varken dit? wiens vader schoot dit varken dood. $\mathrm{ija} \mathrm{n} \mathrm{ang}$ à $\mathrm{ma}$ e: ik bezitter ervan vader den, míjn vader.

jàko: wordt tevens bij de vervoeging van werkwoorden gebezigd wanneer men kort en met nadruk antwoordt op 'n vraag. Sanne dàbàikoh? wie gaat, jàko ikoh: ik ga; jàko éreïh he: ik weiger het.

Voorts gebruikt men 't in de grove spreektaal en aan de kust waar de Ambonsch Maleische invloeden zich hebben doen gelden. Instede van à bà $\mathrm{s}$ à $\mathrm{fe} h \mathrm{~T}_{\mathrm{o}}^{\prime} \mathrm{e} \mathrm{s} \mathrm{i}-\mathrm{t}$ à $\mathrm{m}$ a n $\mathrm{ak} \mathrm{ed} \mathrm{h}$ à $\mathrm{m}$ a $\mathrm{t}$ : ik koop Tesi's vaders visch, zal men zeggen jàko sàfeh $\mathrm{T}$ e s i - $\mathrm{t}$ à $\mathrm{ma} \mathrm{nak}$ ed hà $\mathrm{mat}$.

De accusatiefvorm van $\mathrm{j}$ à ko na verba transivita en voorzetsels die den accusatief bij zich hebben is kà no in den nederigen of verkleinvorm hà $\mathrm{o}, \mathrm{b}$ à $\mathrm{rah} \mathrm{kilih}$ kàno: kittel mij niet! àman dàeflalih hàno: vader sloeg mijtje; dàbàrah 
bosih-sèfen ěngeih kàno: dat niet plots voor den dag kome, boosheid in de richting van mij; word niet plotseling boos op mij; moesik kàno: heb medelijden met mij ; moesik hà no: heb medelijden met mij (nederig) met mijtje, mij kleintje.

Àtar pol'pa di doeeprèpak ${ }^{25}$ ) fèneh:

slaven veertig die zeiden zeggende:

25). doeeprèpak: doe + ep + r èpa(h) + k.

rè pah: 't stamwoord zeggen, praten, spreken.

lèpah: zeggen, praten, spreken (Tihoelale, Roemah kai, Haroekoe, Sàpàroea, Noesa laoet) rèpah (Kàmarian).

prefix e $p$ geeft in de L. E. aan de verba 'n frequentatieve beteekenis.

hàga h: volgen, volg; e phàg a h: achtervolgen, najagen, jagen, op jacht zijn :

goeseh: 'n booze bui hebben; epgoeseh: mopperen, voortdurend over iets ontrevreden zijn;

haїk: al, reeds; Mal. Soedah. ephaïk: verbieden, telkens verbieden, letterlijk voortdurend haïk: tot iemand roepen;

$\mathrm{h}$ à $\mathrm{mah}$ : zoeken, e $\mathrm{ph}$ à $\mathrm{mak}$ : voortdurend iets bij elkander zoeken, overeenstemmen.

$\mathrm{h}$ à $\mathrm{kah}$ : in allerlei richtingen met rotan 'n deur vastbinden, e $\mathrm{ph}$ à $\mathrm{kah}$ : kattekwaad uitvoeren;

$\mathrm{h}$ à $\mathrm{tak}$ : e phà $\mathrm{tak}$ : offeren, offers brengen;

helak: ephelak: prijzen, overvragen;

hiboeh: ephiboeh: kleedingstukken aantrekken.

temah: eptemah: kleedingstukken (broeken) aantrekken;

hitih: om den hals vasthouden om steun te hebben bij 't loopen, bijv. van 'n gewonde; ephitih: voortdurend iemand om den hals vast houden;

karoh: in 't slijk liggen, e pkaroh: zich in 't slijk wentelen van varkens;

lalih: fout, eplalih: fouten maken;

leak: opbergen, bewaren, e pleak : laden, goederen in 'n prauw; $\mathrm{s}$ à $\mathrm{ma}$ : e psà $\mathrm{ma} \mathrm{k}$ : deelen maken, verdeelen;

$\mathrm{s}$ à $\mathrm{pa} \mathrm{h}$ : haken, e psà $\mathrm{pah}$ : voortdurend ergens aan haken, toevallig telkens blijven haken;

taoen: vol. adject., e ptaoek: vullen;

"T o ea n-Ko-Là to e d à bà k a la k kà".

Meneer-de-Vorst roept u. 


\section{Bèko Kà Lampo dàhaïh ro. ${ }^{26}$ )}

- Hierop Kà Lampo volgde ze.

26). ro.

ro is de accusatief-vorm van 't persoonl. voornw. $3^{\circ}$ pers. meervoud sira.

Prof. Joker zegt in zijn "vervoegde werkwoordsvormen blz. 277 r. 16 v. o. "Nu is het element $\mathrm{ra}$ in het volledige voornw. van den $3^{\text {en }}$ pers. meerv. waarvan wij als algemeene vorm sira kunnen stellen (het spatieeren is van mij) toch stellig hetzelfde als het honorifieke prefix ra, bijv. in Jav. rama».

Verder op blz. 278 r. 6 v. o. "Dat een voornaamwrd. van den derden pers. meervd. ook die functis hebben kan (onbepaald "men») blijkt voldoende uit het oud.-Jav. sira én uit den verkorten vorm $r$, vrgl. voorts de functie van het prefix in $\mathrm{rama}$ en dergelijke».

Prof. Kern. Fidji enz. blz. 21 "Het mv. ira is identisch met Niasch, ira, Pamp. ila; ra met ra en la in dezelfde talen; als bestanddeel van 't mv. zeer gewoon o. a. Tag. sila; Bul. sera. Een variteit van ira en $r a$ is Iloko ida en $d a$, als nominatief».

't Aanwijzend persnl. vrnw. derde pers. mrv. in de L. E., is sira. 't welk gebezigd wordt:

a. na vragen, bijv. san sira doetàhah kaoe-poen na e : wie hakten om dezen boom? sira: zij.

b. bij vervoeging der werkwoorden, wanneer de nadruk op 't persnl. vrnw. valt; sira doekòrah he: zij steenigden hem; c. in de grove en slordige spreektaal aan de kust bij de vervoeging der verba. sira ikoh: voor sir doebàikoh: zij gaan; sira dàteh haïk: si r doebàdàteh haï k: zij zijn reeds aangekomen.

In den vervoegden werkwoordsvorm gebruikt men steeds sir; sir doebàlàtah: zij hakken, sir doeepleak: zij laadden; là sir d o e ef ràkeh he sal'sà lak: zij zouden hem grijpen.

De accusatief-vorm van sira is ro: ze; de verkleinvorm van ro: ranno: zetjes.

rin dàpòtoh ro: hij verbrandde ze; sir doekòrah ranno: zij gooiden zetjes (bijv. kuikentjes) met steenen dood.

Valt op ze de nadruk en moeten we dus in den accusatief vertalen hen, haar dan is dit in de L. E. kor ro: 
We hebben hier in kor: den plur-vorm van ko 't welk wij boven aantroffen in Ko Là toe: de koning ro: is 't beplnd. lidw. meerv. en luidt de letterlijke vertaling dus ze de, d. i. hen, haar.

rin dà pòtoh kor ro: hij verbrandde hen, ha ar; gèb' eplàtat to doepéfmàtak sàtaïk kor ro: de soldaten schoten hen allemaal dood.

Van sira is verder gevormd sir roea: zij twee, getweeën. Sir roea doelèbah faf'àba e : zij twee, zij tweeën droegen het boschvarken; kalak sir roea bẻkah: roephen getweeën maar.

Ook is van sira gevormd sirro: en (met), wanneer er sprake is van twee personen bijv. Tjaki sirro Ròhin; Tjaki en Rònin, Martha sirro Maria: Martha en Maria.

In stede van: "bèko Ká Lampo dàhaïh ro» hierop volgde Kà Lampo ze, kan men zeggen: «bèko Kà La mpo dàhaïh kor ro»: maar moet men dan vertalen: hierop volgde Kà Lampo hen.

Là betoen sir doesoeb'dàteh haïk ${ }^{2}$ 7) Toean-Ko-Làtoe ten tijde ervan zij aankwamen reeds Meneer-de-Koning dàfètek-ěnge ïh ${ }^{28}$ ) Kà Lampo e fèneh :

zeide-tot Ka Lampo zeggende: sis doesoeb' dateh haïk.

27). doesoeb' dàteh: samengest. uit doe + soebah + dàteh. soebah: naar buiten komen, naar buiten gaan; dàte $\mathrm{h}$ : komen tot, komen aan; s o e b'dàte h: naarbui komen komen tot aan, v. d. aankomen.

haïk: al, reeds, klaar; hulpwoord om den volkomen tijd uit te drukken; doesoeb'dàteh haïk: aankwamen reeds, al, aangekomen waren. dàf èt e k- ěng eïh :

28). fè tek: zeggen, spreken, wanneer men de woorden van 'n ander aanhaalt, die gericht waren tot spreker of tot 'n derde, die ' $n$ bevel of berisping inhielden.

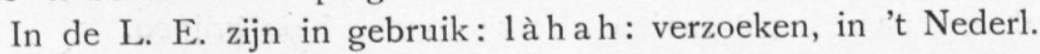
te vertalen met aan, van; oeteh: ten bate van, aan; éngeih: in de richting van, aan, tegen, tot.

1 àhah: verzoeken, wordt derhalve gebezigd bij die werkwoorden, die 'n vraag, verzoek, in vriendelijken, beleefden toon gesteld, bedoelen. ri n dà ěn ikah-là ha h kàno fèneh: nam à $\mathrm{ma}$ tà $\mathrm{fi} \mathrm{do}$ ? hij vroeg aan mij zeggende, waar is uw vader? 
à enàhoeh-làhah he fène $1 \mathrm{a}$ rin dàhàmah nang koepe e: ik sprak met hem af dat hij mijn hengelstok zocht.

à man dà ědoeëh-oeteh kàno làboen sò pan-solan emsian: vader gaf aan mij een prachtig-mooie kabaja; in an dàlaïk ië-ěnân oeteh gẻb'epkàsiat-malhòrot di e: moeder gaf eten aan dien doodongelukkigen mensch.

lèber re dàsoeboeh-ěngeïh kàno fèneh: "maoe kah koelen;» de koning vloekte mij zeggende: kat vreet z'n maag op! géb'eptòket te dàsimah-ěngeïh ànats ékolar ro: de onderwijzer berispte de schoolkinderen.

loek boah ${ }^{29}$ ) nang fàfor na penik ke ${ }^{30}$ ).

29). loek boah: samengesteld uit là +oek boah.

't Persnl. vrnw. $2^{\circ}$ Pers. enkvd. bij de vervoeging van werkwoorden is oek, oek dábáboah: gij fokt; oek dàboah: gij foktet, 1 à oek dà bà bo $\mathrm{ah}$ : dat gij fokket.

Uit de samentrekking van $1 \mathrm{a}+$ oek tot 1 oek met den imperatief vorm van 't werkw. boah: fokken heeft men derhalve 't bevel $g$ ij fokt, loek boah. Deze imperatief is minder scherp dan kaë boah, ka ë: jij! gij! Zeer sterke grove emphatische vormen van den Imperatief zijn: loek boah gah; en kaë boah gah. Vooral 't laatste is zeer grof.

De emphatische nominatief vorm van oek is oekkoe. In dit laatste $\mathrm{koe}$ is de o van ko geassimileerd met de oe van oek. oekko en dus oekkoe: beteekent niet anders dan de $\mathrm{g}$ ij, dus gij en niemand anders. Dit is tevens in gebruik bij 'n zachten, beleefden imperatief oekkoe boah: gíj. (en niemand anders) voed op, fokt. Deze vorm kan weder versterkt en verscherpt worden door gah. oekkoeboah gah: gíj, jij voed op, fokt. of met 'n object. oekkoe gah boah fàfor ro: jij! fokt de varkens, en dit dan op 'n vraag als: wie toch moet de varkens fokken?

o e kko e dàbàlàtah: gij hakt om, en hij doet bijv. wat anders. oekkoe làtah: gij hakt om. Zachte, beleefde imperatief,

30). penik ke.

penik: maar, vooreerst. penik ke: voor eerst het. In dezen zin is de beteekenis dus na 't bevel dat gegeven wordt: dit is 't eerste, dit is 't maar wat gij te doen hebt.

loek boah nang fàfor na penik ke: gij fokt mijn varkens deze vooreerst, gij fokt deze m'n varkens maar. 
Bèko Kà Lampo dàikoh pà dàpoenah ${ }^{31}$ ) 1 iat ${ }^{32}$ ) òto ${ }^{33}$ ) Hierop Kà Lampo ging om maakte kot(ten) in moea e pà dàibik fàfor di e. bosch het om oppaste varkens die.

31). d à poen a h.

poenah: doen worden, maken, act. transit. vorm van poena: worden.

32). liat: kot voor varkens. substant. gevormd door suffin t van 't werkwoord liah: 'n kot maken om varkens in te doen, liak: varken in 'n kot doen.

Zelfstandige naamwoorden op ' $\mathrm{t} t$ die van werkwoorden zijn afgeleid duiden 't middel of werktuig aan waardoor of waarmede de handeling wordt verricht.

à $\mathrm{pih}$ : knellen, à $\mathrm{p} \mathrm{it}$ : schorpioen ;

ateh: dekken, atet: atap;

àtih: sagoepap oprollen tot 'n klodder, àtil: houtje om sagoepap op te rollen;

bidoh: visschen met 'n werpnet; bidoeh: iets met 'n werpnet visschen; bid oet: werpnet;

édihih: kammen, ědihit: kam;

$\mathrm{k}$ à $\mathrm{h} \mathrm{h}$ : roeien, $\mathrm{k}$ à $\mathrm{h}$ t: roeispaan;

ipik: in pand nemen, ipit: pand;

siroeh: opscheppen, siroet: lepel;

liëh: 'n stem hebben, liët: taal;

iris: (mal. hiris: klein afgesneden stukje; menghirishiris: in kleine stukjes snijden, kerven) irit: mes;

soök: strikken, soöt: strik;

tèfeh: kloppen van 't binnenste van den schors van den koem'kine 'n boomsoort, om er dan lendengordels en sarongs van te maken, tèfet: soort hamer waarmede met den schors klopt;

wihih: in de hand hangende dragen, wihit: touw, waarmede men iets ophangt;

pòëk: 'n dier den bek vast binden dat 't niet bijten kan, pò ët: muilkorf.

péleh: tegenhouden, enbèlet: staketsel;

lèleh: teruggaan, eslèlet: teeken om te doen teruggaan; van lèbah: met z'n tweeën of meerderen dragen aan 'n stok; hiervan kà lèbat: draagstok. 
Dit $\mathrm{k}$ à: is 'n verkorting van kà o e: hout. De meeste substantiva gevormd met dit $\mathrm{k}$ à en 't werktuig aanduidend waarmede de handeling wordt verricht, eindigen op 1 .

tà $\mathrm{rih}$ : vegen, kà ta ril: bezem, ro es a h: met 'n stok vruchten afstooten, kà roesa l: stok met haak waarmede men vruchten afstoot of trekt; soedah: overtrekken water, kà soeda l: brug; kòkih: overtrekken water, k à kòkil: brug ; kleiner dan kà soeda 1, vonder, vlonder; soemah: splijten, kà soema l: kegge, wig; loengah: 't hoofd ergens opleggen, kà loenga l: houten hoofdkussen, kòïh: scheppen, kà kòil: schepper, hoosvat; da reh: steunen, kà da re l: stut.

De anorganische $t$ dient voorts tot vorming van den zelfstandig naamwoordelijken vorm der verba, welke substantiva tevens dienen om 't product der handeling te benoemen.

$1 \mathrm{à} \mathrm{h} \mathrm{a} h$ : verzoeken, e $\mathrm{n} \mathrm{l}$ à h $\mathrm{t}$ : 't verzoeken, ('t vragen); verzoek; kalak: roepen; ěnalat: 't roepen, geroep; peswalih: vermanen; peswalit: 't vermanen, vermaning; sòmoh: vergelden van den bruidschat, es n ò mot: 't vergelden; vergelding; doleh: goed met goed vergelden, endolet: 't vergelden, vergelding; eflèsah: tafeldekken; eflèsat: 't tafeldekken, disch; holoeh: juichen, enholoet: 't juichen, gejuich; heah: rumoer maken, enheat: 't rumoer maken, rumoer; la ïk: eten geven aan; enlaït: 't eten geven aan, 't geven, gift, geschenk; boesoek: aanklagen, e mboesoet: 't aanklagen, aanklacht; poenah: doen, maken, empoenat: 't doen, 't maken; daad; pempoenah: voortdurend doen, pempoenat: 't voortdurend doen, gedrag; dèfoh: blijven, dèfoek: ergens verblijven, bewonen; endèf o et: 't verblijven, verblijf; bà geh: liggen, enb à ge t: 't liggen, ligging; s i o e k: zenden, e sn i o et: 't zenden, zending; sàfeh: koopen, es nàfet: 't koopen, koop; $\mathrm{kah}$ : eten, enkât: 't eten, nom. verb.; ěnât: eten, subst; ikoh: gaan, ikoek: iets begaan, bijv. 'n pad, 'n weg; enjikoet: 't begaan, reis; tangih: weenen, huilen, ěn a ngit: 't weenen, 't huilen, geween, gehuil; seroh: weven, seroeh: iets weven, esneroet: 't weven, weefsel; pèhah: gisten, pèhat: koolzuur bolletjes bij 't gisten.

Door samenstelling met de woorden gèb' verkrt. van gèbah: mensch, ië: ding, elet plaats voor, om te, elen: plaats er van, en wàhan nagelaten spoor, indruk; worden van de zelfst. nwdl. werdwoordsvormen substantiva gevormd. 
gèb'ěnalat: mensch op wien 't roepen is toegepast, geroepene, gast; ië es nò mot: ding, goed waarmede men bruidschat vergolden heeft; $r a h$ ' is' esnò mot: vergeldingsgrond; gèb' emboesoet: aanklager; empoenat wàhan: 't doen, 't maken indruk er van; daad; pempoenat wà han: 't voortdurend doen indruk er van, gedragingen; gedrag; elet-endè foet: plaats-verblijven, verblijfplaats, woonplaats; e ndè foetelen: verblijven plaats er van, verblijf, 't verblijven nagelaten spoor, indruk er van, plaats waar iemand verbleven heeft; elete n bàg e t: plaats liggen, slapen, plaats waar slaapt, slaapplaats ; en bàg e t-e len: 't slapen liggen, plaats indruk, nagelaten spoor er van, plaats waar iemand gelegen, geslapen heeft; ěnât: 't eten, ië ěnât: goed eten, spijze, sagoe, rijst, gierst, veldvruchten, de hoofdschotel, geen bijspijzen.

Voorts dient de anorganische $t$ aan 't eind van 'n woord tot 't vormen van adjectiva.

$1^{\circ}$ van substantiva bijv.

boti : albino, botit: wit;

koni: kurkema, konit: geel;

k à b o e : modder, kà b o e t : modderig ;

$\mathrm{r}$ à $\mathrm{h}$ à : bloed, $\mathrm{r}$ à hà $\mathrm{t}$ : bloederig, met bloed bevlekt.

bijv. làboen botit: witte kabaja, witte kabaja's; láboen botit te: de witte kabaja, làboen botit to: de witte kabaja's; milòlot konit to: de gele hoofddoeken; enheloet konit: gele lendengordels; neten kàboet: modderige plaats, plaatsen; neten kàboet te: de modderige plaats; net' kàb oet : modderpoel, is 'n samengesteld woord; gèb' fah' ràh a t: mensch handen bloederig, moordenaar.

$2^{\circ}$ van die woorden welke wij gebruiken om abstracte begrippen uit te drukken en qualificatieve woorden zijn bijv. lang, groot, dik, zwaar, enz.

ha ; groot, hât: groot, adject.

gòs a : goed, gòs at: goed, adject.

mite : zwart, mitet: zwart, , rema: lang, remat: lang, ", ròï: gering, klein, ròït : gering, klein, adject.

breoe: klein, breoet: klein, adject.

mòda: frisch, mòdat: frisch, ",

gaw a : blank, gawat: blank, "

bèha: zwaar, bèhat : zwaar, " 
pòto: warm, pòt ot: warm, adject.

fòra : pedant, for at : pedant,

lina: helder, 1 in at: helder,

enz.

hoema na dà ha: huis dit is groot; dit huis is groot, hoema hât na: huis groote dit, dit groote huis; kèhet di doe rema: zwaarden die lang zijn, kèhet remat di : zwaard, (zwaarden) lang, (lange) dat, die; dat lange zwaard, die lange zwaarden; wàga e da gosa: de prauw is goed; wàga gòsat te: prauw goede de, de goede prauw; wà e dà $\operatorname{moda}$ : water het is frisch, het water is frisch; wà modat te: water frissche het, het frissche water; fator ro doe bèha: steenen de zijn zwaar, fàt or bèhat to: steenen zware de; de steenen zijn zwaar, de zware steenen.

$3^{\circ}$ van dien vorm van 't werkwoord dien wij gewoonlijk participium praesens noemen.

tewah: weten, e m tewah : wetende, gèb’ e p tò ket di dà emtewah: mensch voortdurend aanwijzen, v. d. gèb' eptòket: onderwijzer, die is wetende, kundig, knap; emtewat: knap, kundig, geb' ep tòket en tewat di: onderwijzer kundige, knappe die; die knappe onderwijzer.

$\mathrm{h}$ à $\mathrm{m} \mathrm{h}:$ boven drijven, e $\mathrm{m} h$ à $\mathrm{m} \mathrm{a} h$ boven drijvende, e $\mathrm{m}$ $\mathrm{h}$ à $\mathrm{m}$ a $\mathrm{t}$ : licht, (niet zwaar).

dilah...., emdilah: rad van tong; emdilat: radtongig; g eà ....., e mg eà : beschaamd, e mge a t: beschaamd, adj.; fò $\mathrm{do} \mathrm{na}$ d a e $\mathrm{mhàmah}$ : deze draagmand is licht; sir doerengah fòdor em hamat to: zij droegen (met 'n draagband voor 't voorhoofd) de lichte draagmanden; emhoeka emdilat di e: diè radtongige maagd; boedihtàma e mgeat na: deze beschaamde aartsleugenaar.

$4^{\circ}$ van sommige verba.

belwatak: grootspreken, belwat at : grootsprakerig;

kà ròs a h : grof in zijn manieren zijn, kà rò $s a t$ : grof ;

$5^{\circ}$ van to ehà : te zamen met, ermede;

laï-enjolit-toehat: deel, aandeel, 't terugkeeren naar huis gaan, ermede, dat deel bij 'n maaltijd dat de gasten krijgen om mede naar huis te nemen; er mede naar huis gaande aandeel.

33). òto: te, op, in, met accusatief.

òto Foe' Boeroe e: op Boeroe; 
òto hoema lalen ne: in huis binnenste er van het in het huis;

òto fen' ektinan Ambon ne: te, in, hoofdstad Ambon de, in de hoofdplaats Ambon, ter hoofdplaats Ambon.

Hierop glng Kà Lampo om varkenskotten in 't bosch te maken om die varkens te bewaken.

Lalen sà Kà Lampo dàhòsak-soep-soepak ${ }^{34}$ ). maal er van eens Kà Lampo stond op zeer vroeg.

34). hòsak-soep-soepak: samengesteld werkw. uit hòsak: opstaan, + soep-soepak:

soepak afgeleid van soepan: morgen (den volgenden dag). so epan mà ikoh: morgen wij (incl.) gaan, morgen gaan wij.

Bij de woordherhaling treffen we aan:

$1^{\circ}$ herhaling van 't geheele woord of van zijn afleiding.

$2^{\circ}$ herhaling van ' $n$ gedeelte van 't woord of 'n gedeelte van zijn afleiding.

Woordherhaling bij werkwoorden beteekent herhaling, voortduring of groote of geringe mate van 't geen door 't werkwoord wordt bedoeld en dit naar 't zinsverband.

Herhaling van 't geheele woord.

wiloh: heen en weer bewegen, wiloh-wiloh: voortdurend heen en weer bewegen, schommelen (ook wiloh-waloh 'n weinig schommelen;

mihih: verheugen, mihih-mihih: voortdurend verheugen, zeer verheugen; 'n beetje verheugen;

feoh: met z'n velen blijde zijn, zich verheugen;

feoh-feoh: zich met z'n velen voortdurend, zeer verheugen, blijde zijn; 'n weinig verheugen met zijn velen:

fitoer: overdenken; fitoer-fitoer: voortdurend, ernstig overdenken;

goh: langzaam gaan, goh-goh: zeer langzaam gaan;

kèleh: dwingen iemand, kèleh-kèleh: voortdurend, zeer dwingen iemand.

Herhaling van de geheele afleiding van 't grondwoort ětjoebik: springen, ětjoebik-ětjoebik: voortdurend springen, sprongen maken;

eptoedoeh: met de holle handen 't water slaan zóó, dat knallende geluiden gehoord worden, eptoedoeb-eptoedoeh: dit voortdurend of in hevige mate doen. 
N. B. eptoedoeh: is reeds frequentatief.

Herhaling van 'n gedeelte van 't woord of van 'n gedeelte van de afleidingen.

$\mathrm{s}$ à g e h: herhalen, s a g - s à g e h : voortdurend, goed herhalen ; langzaam herhalen naar 't zinsverband.

soeboeh: noemen, soe'soeboek: voortdurend noemen, voor iemand goede woorden spreken, pleiten voor iemand.

eptaoek: vullen, iets met iets anders vol maken;

epta o e-eptaoek: voortdurend maar vullen, zeer vol maken;

epsà pah: ergens aan blijven haken, e p sap-epsàpah: voortdurend, erg, ergens aan blijven haken;

epsiak: verzamelen, epsi-epsiak: goed, terdege voortdurend bij elkander brengen, verzamelen;

epsėseh: op rijen zetten, arangeeren, epsès-epsèseh: voortdurend, goed op rijen zetten, arangeeren;

epsèsah: troosten, epsès-epsèsah: voortdurend, zeer troosten; pěsėsan: elkander troosten, pěsès-pěsėsan: elkander voortdurend, zeer troosten.

Door herhaling van 't geheele woord of de herhaling van 'n gedeelte hiervan worden substantiva gevormd.

itih: flikkeren, itih-itih: vlag;

litih springen, litih-litih: vloo;

lawe: zeewaarts, lawe-lawe: zee waar geen land meer te zien is; zeer ver in zee.

sà lah: missen, (Mal.) sa l-sàlah: djimat, afweermiddel ; wà s a ....? ? w a s - wà s a : geelkoper;

bòboh: sluiten van de oogen, sà bòbòbok: 'n oogensluiten, 'n oogenblik;

boti: albino, wit; bot-boti: morgenschemering.

Woordherhaling of herhaling van 'n gedeelte van 't toestandswoord, of dat 't welk 'n eigenschap aanduidt geven naar 't zinsverband te kennen, dat 't woord waarop 't adjectief betrekking heeft deze eigenschap in zeer groote of in geringe mate bezit.

boti: albino, wit, boti-boti: zeer wit, beetje wit;

emkèle: hoog, emkèle-emkèle: zeer hoog, nogal hoog;

breoe: klein, breoe-breoe: zeer klein, tamelijk klein;

geoe: vlug, geoe-geoe: zeer vlug, nogal vlug;

moda: avondwind, mod-moda: zeer frisch, weinig frisch; mite: zwart, mit-mite: zeer zwart, weinig zwart; 
emtanga: steil, emta-tanga: zeer steil, tamelijk steil; ròïan: klein, rò-ròïan: zeer klein, tamelijk klein:

Herhaling van 'n adverbium of van 'n gedeelte hiervan beteekent 'n versterking, hooge of geringe mate naar 't zinsverband dit eischt.

fili: tijd, fili-fili: zeer lang van duur, 'n beetje lang;

lân: tijd, lân-lân: voortdurend, altijd maar;

hèlen: gauw, hèlen-hèlen: zeer gauw, 'n beetje vlug;

eptilo: dadelijk, eptilo-eptilo: plotseling;

$\mathrm{g}$ à $\mathrm{t} \mathrm{k}$ : morgen, gà $\mathrm{t} \mathrm{a} \mathrm{k}$ - $\mathrm{g}$ à $\mathrm{t} \mathrm{k}$ : iederen morgen, dagelijks, voortdurend;

tilo: dadelijk, til-tilo: terstond;

rò ho: langzaam, roh-rò ho: zeer voorzichtig, zeer langzaam, 'n beetje voorzichtig, langzaam;

emsikan: alleen, emsik-emsikan: geheel alleen;

emhewak: zelf, e mhew-emhewak: zelf alléén;

tòbo: gewoon zijn, tob-tòbo: zeer gewoon zijn, ergens mede;

eskèlen: bijna, eskèl-eskèlen: bijna!

r à h e k: slechts, r a h'-rà h e k: slechts! maar!

moh: niet neen, moh-moh he: volstrekt niet het.

soepan: morgen, soep'-soepan: morgen vroeg;

soep'-soepak: 'smorgens vroeg in samenstelling met verba. hòsak-soep'-s oe pak: vroeg-opstaan.

Herhaling van telwoorden in hun geheel of 'n gedeelte dier woorden beteekent:

$1^{\circ}$ van emsian: één, emsiam-emsian : een enkele;

$2^{\circ}$ elk afzonderlijk, één voor één, ieder. emsian-emsian;

$3^{\circ}$ met (ons, hun -) en, of twee aan twee, drie aan drie enz.

roea: twee, roe-roea: met ons, hun tweeën; twee aan twee, drie aan drie;

tèlo: drie, tel-tèlo: met ons, hun drieën;

pa: vier, pa-pa; lima: vijf, lim'-lima; ne: zes, ne-ne ; pitoe: zeven, pit'-pitoe; etroea: acht, etroea-etroea; etjia: negen, etjia-etjia; pòlo: tien, pol'-pòlo: met ons, hun tienen; tien aan tien; pol'-pòlo: beteekent tevens: allemaal.

pol'temsia: elf, pol'temsia-pol'temsia: met ons, hun elven; elf aan elf, pol'temroea: twaalf, pol'temroeapol'temroea: met ons, hun twaalven, twaalf aan twaalf; pòlo geran tèlo: dertien, pòlo geran tèlo-pòlo geran tèlo: met ons, hun dertienen, dertien aan dertien, enz. 
Gedeeltelijke herhaling van paskemak: alle, exclusief spreker, hansiak: alle inclusief spreker geeft 't volstrekte, de versterking van alle te kennen, allemaal.

paske'paskemak; hansi' siak; hansi'-hansiak.

to $\mathrm{e}^{35}$ ) dàëpmàtah-sàtaïk ${ }^{36}$ ) fàfor di e, en doodde-totaal varkens die,

35). toe : voegwoord en,

to eh: voortzetsel met,

to ehà : te zamen met, er mede.

36). dà ë $\mathrm{pm}$ à t a h-s à t a ̈ $\mathrm{k}$ : samengest. uit : d à ë $\mathrm{p} m$ à $\mathrm{tah}$ : doodde $+\mathrm{sàta} \ddot{k}=\mathrm{sa}+\mathrm{ta} \ddot{i}+\mathrm{k}$ : letterl. één $\mathrm{tain}:$ afval er van, maken, vandaar geheel en al, allemaal, totaliter, totaal.

bèko rin dàegoeh ikoenno pà dàik'vervolgens hij nam staarten hun om gaan bezigen sékak ${ }^{37}$ ) kor ro òto kaboet te. om te steken hen in modder den.

37). sèkah: steken, sèkak: gebruiken om te steken.

Bisoek ${ }^{38}$ fil di rin dàïkoh toe dàëprèpak-làhah Voorbijgaan van dat hij ging en zeide tot Toean-Ko-Làtoe e fèneh:

"Meneer-den-Vorst » den zeggende:

38). bis oek: letterl. voorbij doen gaan; voorbijgaan is in de L. E. 'n reflex: werkwoord. Zie: De reflex. werkw. sir doebisoek kor haïk là ngin'soepan.

zij deden voorbijgaan ze al op heden-morgen; zij gingen dezen morgen al voorbij, zij passeerden van morgen al. beton pila lalen à bisoek kan hä̈ ? nacht hoeveel ik voorbij doen gaan mij reeds? Voor hoeveel nachten passeerde ik reeds?

bisoek fil di: nadat, daarna, vervolgens.

nam fà for paskemak ${ }^{39}$ ) doemòdoh-hònot-hanoeh ${ }^{40}$ ) uw varkens allemaal smoorden, verzopen

fidi kàboet te

in modder den

39). paskemak: ook meermalen uitgesproken peskemak afgeleid van kema: voltallig, geheel; etkemat: geheel, voltallig, adject. hoema etkemat te: het geheele huis; hoem' etkemat: huisgezin; paskemak: allemaal. 
40). mòdoh-hònot-hanoeh: smoren, verzuipen, is 'n samengesteld woord; de beteekenis der verschillende samenstellende woorden, is mij tot heden onbekend gebleven.

Wahang di sir doeik'kalih kàboet te boe ${ }^{41}$ ) sir Oorzaak reden dat zij gingen graven modder den maar zij doebetah rahek ${ }^{42}$ ) fàfor ikoenno.

vonden slechts varkens staarten hunne.

41) boe: tegenstellend voegwoord maar.

rin dàěnikah boe moh, dàlàhah boe moh, dàegoek

hij verzocht maar neen, vroeg maar neen, mede nam rahek ke.

maar het; hij verzocht noch vroeg maar nam het mee.

42). ràhek: slechts, maar; met gedeeltelijke woordherhaling 'n versterking aanduidende $\mathrm{rah}$ ' $\mathrm{r}$ à hek: slechts! maar!.

Béko Toean-Ko-Làtoe e dàolih toe dàsioek Daarna Meneer-de-Vorst de ging naar huis en zond $\mathrm{nak}$ àtar-pol'pa pà doeik'làtah ${ }^{43}$ ) oeka 44) pà zijn slaven veertig om gingen hakken bamboe om d o egà roeh ${ }^{45}$ ) ěroenga n ${ }^{46}$ ) sà .

makkten kot 'n.

43). doeik'latah: samengesteld uit doe + ikoh + làtah iko h: gaan; là $\mathrm{ta} \mathrm{h}$ : hakken:

44). o eka: bamboe, verschillende soorten zijn:

e mnàkoen, bò lo, e pit, kàwân, nemoe, kà kasel, ten a n, emngàda, t in a n.

45). d o e gà r o e h, gà r o e h : werken, vervaardigen, maken.

46). éroengan: krot, inderdaad 'n soort kist van bamboe gemaakt waarvan men den deksel oplichten kan en waarin men varkens vervoert. In dergelijke kisten worden de varkens vaak eenige weken opgesloten om ze verder te mesten tot den dag waarop ze voor de een of andere feestelijke gelegenheid worden geslacht. Men steekt ze dan met 'n lans dood door de reten tusschen de bamboestokken.

$\mathrm{Bij}$ huwelijk of vredesmaaltijden brengt men de feestvarkens in dergelijke kisten, door mannen aan 'n bamboe-draagstok gedragen, vaak naar 't dorp waar 't feest zal gevierd worden. 
Là betoesir doepoen' màtak haïk ${ }^{47}$ ) ěroengan di e, Toen zij gereedmaakten reeds, kot dat sir doeòsok Kà Lampoe òto éroengan lalen zij in deden Kà Lampo in kot binnenste ervan ne pà doeik'pòlok ke fi di olat te ${ }^{48}$ ). het om gingen-verdrinken hem te daar zee de.

Bèko sir doelébah he $\mathrm{gam}^{49}$ ) lalat te ${ }^{50}$ ) toe doetàtik Daarna zij droegen hem naar strand het en zetten neer penik ke fi di ta pà doeolih-egoeh-lafat toe eerst hem te daar om gingen halen leeftocht en doe barbâk ${ }^{51}$ ) emsik-emsikan Kà Lampoe. lieten achter geheel alleen Kà Lampo!

47). La betoe sir doepoen'màtak haïk.

poen'màtak: samengesteld uit poenah+màta $+\mathrm{k}$ :

De L. E. heeft 't werkwoord poena: worden.

$\mathrm{R}$ in dà bà poena géb'e p tò ket: hij wordt onderwijzer;

Fidir dà poena emrimo: Fidir werd dorpsbode.

Van dit werkwoord worden is gevormd 't act. transit. werkwoord doen worden. maken: poenah.

Sanne dàpoenah i di e? wie deed dat?

Tiris se dàpoenah he: Tiris deed het.

Lokis se dàbà poenah i na e: Lokis doet dit.

On san sira doepoenah ië sà gam na?

Wie zij deden ding een gelijk dit?

Wie deden zoo iets?

Met 't werkwoord poen ah worden samengestelde werkwoorden gevormd, die dan de beteekenis hebben van maken dat 't object de eigenschap krijgt of ondergaat wat in de tweede helft van de samenstelling wordt bedoeld.

In 'n enkel geval, wordt 't geheele werkwoord poenah in die samenstelling gebruikt, meerendeels echter de af korting poen.

In dit werkwoord poena: worden, hebben we zonder twijfel 'n afgeleid werkwoord van 't subst. poe: oorzaak, stam, waarvan't zelfst.nw. poen: stam, ltl. stam er van, bia poen: sagoeboom, tèhat poen: ijzerhoutboom, lapit poen: beringin boom, enz.

Van poe is gevormd door reduplicatie pépoe: van 'n stam voorzien zijn; fat'p époe: steen van 'n stam voorzien, rotsblok.

Voorbeeld van samenstelling met 't geheele woord poenah, poenah-neïh: werken, arbeiden;

Dl. 75 . 
Samenstellingen met poen'

poen'màtak: gereed maken, poen'gòsah: iets goed maken, herstellen; poen'sépoh: iets afmaken, uitmaken; poen'pisoek: iets maken dat 't gepasseerd, voorbij is, iets wegmaken; poen'sedoeh: iets maken dat men er om lacht, belachelijk maken; sedoeh gekscheren; iets maken dat men er mede gekscheert;

poen'emtoroh: iemand doen zwijgen; poen'faïh: maken dat men faïh! bah! van iemand zegt, bespotten;

poen'fah: maken dat iets geur heeft, met 'n smeulend stuk hout rond den tuin loopen zoodat er rook- en menschenlucht aan den tuin gegeven wordt waardoor wilde varkens en herten op 'n afstand worden gehouden.

De zelfde beteekenis als poen' hebben pong en po in eenige samenstellingen. Matthes Boegin Gram. blz. $82 \S 64$ ltl. f. pong'faïh: poen'faïh; pong'fâh: poen'fah ;

potaïk: tot taï: afval, vuil, maken iets; en hiervan weer poen'potaïk: 'n versterkte vorm van potaïk: vernielen, vernietigen; bèleh: tegenhouden, pobèleh: maken dat iets tegengehouden wordt, verhinderen, beletten;

Naast dit prefix po heeft men 't prefix pe, 't welk de zelfde beteekenis heeft. Matthes Boegin. Gram. blz. $92 \& 69^{a}$ Lett. h. Mak. Gram. blz. 97 § 180 Lett. k. Het voorvoegsel pi.

gòsa: goed, ̌g g̀sah: goed worden, pegòsak: goed maken, in orde maken; breoe: klein, pebreoeh: klein maken, inpakken; loesah: vol zijn; peloesak: vullen; bah:op de plaats van spreker zijn, pebah: hier achter laten; ědèngan: gebeuren, geschieden, pedèngah: doen gebeuren, geschieden, vervullen, 'n belofte; peroeh: van; roea: twee, in tweeën breken; waroh: meer worden, zich vermenigvuldigen, pewaroeh: vermeerderen iets, vermenigvuldigen iets; moda: frisch, pemodah: frisch maken, verfrisschen.

Uit ěgòsah en ědèngan is reeds gebleken dat bij woorden die met $\check{~}$ aanvangen deze wegvalt en 't prefix pe voor 't stamwoord wordt geplaatst.

Naast 't prefix pe heeft men 't prefix pě met 'n zelfde beteekenis.

giwe: hard, pěgiwek: iets hard maken, verharden; gè hah: lang ergens blijven, pěgèhah: doen vertragen, iemand, iets ergens lang doen blijven; gimel: vertragen act. intrans., 
p ĕgimel: doen vertragen; jaweh: schaduw geven, p $е j a w e h$ : maken dat iets schaduw geeft, pějawek: iets met schaduw doen zijn, maken dat iets schaduw heeft, in de schaduw zetten, leggen, plaatsen; nino: schaduw, pěninoeh : beschaduwen; loekeh: 't uiterste van iets zijn, ergens boven uitsteken; loeken: uiterste er van, takje, twijgje, top; pelloekek: de uiteinden van twee dingen tegen elkander doen zijn, vergelijken; emlosi: afgemat, vermoeid, pemlosih: afmatten, vermoeiën; gètek: kort ademig zijn, pègètek: kort ademig maken; emnàken: gezel, pemnàkek: maken dat iemand 'n gezel heeft, vergezellen.

Verder 't prefix pà met causatief beteekenis als in 't Mad., Mak., Boeg,, de talen van N. Celebes en de Fhilippijnen, Sang. enz. Kern. Fidji enz. blz. 57 r. 5 v. o. van Hoëvell. Iets over de vijf voornaamste dialecten Ambonsche Landtaal. Verba. 't proefix pà blz. 22 .

$\mathrm{kah}$ : eten, pàkah: doen eten, voederen van dieren; lòlo: jong, pàlòloh: jong maken, ontginnen; mènah: voor zijn, mènan: voorste er van, pàmèn $\mathrm{ak}$ : voor zijn toe passen op iemand voorgaan, vooruit loopen, voor iemand loopen; himak: willen, pà himak: zijn wil op iemand toepassen, bedoelen.

Verba act. intrans. die aanvangen met $b$ of $m$ worden tot act. transit. verba gemaakt door 't prefix $\mathrm{p}$ 't kortste rudiment van poenah maar bij die verba wordt de b of $m$ afgestooten.

bodih: vallen, podih: doen vallen, bijv. 'n boom; bèleh: verhinderd zijn, pèleh: verhinderen, tegen houden; bèkah: laat af, vetatief; pèkak: wegwerpen, weg doen, iets nalaten; bisik: nerf uit snijden, pisik: maken dat de nerf ergens uit is, i. c. zijn broekband losser maken; bosih: plotseling te voorschijn komen, treden, boosheid, toorn; posih: plotseling opwekken, naar buiten doen komen; mangik: drogen der borsten, pangik: doen droog worden, roosteren boven 't vuur; mòloh: duiken, pòlok: iets, iemand doen duiken, verdrinken, verzuipen; manoh: drijven, panoek: doen aandrijven, aanspoelen.

N. B. men lette weer op de verwisseling van o en oe.

manoek: landwaarts gaan; panoek: naar 't land doen gaan, naar 't land duwen, drijven, ac. transt.

't Prefix pě geeft aan verba act. transit. 'n frequentatieve beteekenis. 
reïh: weigeren, pěreïh: voortdurend weigeren, pěreïk : iets voortdurend aan iemand weigeren;

s ėkah: steken, pěsékah: voortdurend, bij herhaling steken; sodih: stompen, pěsodih: voortdurend bij herhaling stompen; doleh: goed met goed vergelden; pědoleh: voortdurend, bij herhaling goed met goed vergelden; pèfah: schieten, branden, pěpèfah: voortdurend, bij herhaling, schieten, branden; nikah: verzoeken; pěnikah: steeds verzoeken bij herhaling verzoeken; en à $\mathrm{kah}$ : stelen, pe nà $\mathrm{k}$ a h: voortdurend, bij herhaling stelen.

48). olat: De bewoners der binnenlanden noemen 't meer in 't hartje van Boeroe, olat: zee, (rana: meer), evenzoo de zee rond Boeroe, daar waar nog andere landen te zien zijn. De zee zonder eenig land in 't zicht, de oceaan, noemt hij olat faf'miloen lalen: zee waarvan de oppervlakte is als een en al olie er van, fàfan: bovenste oppervlakte er van; miloen: vet er van, olie;

49). g a m: richting aanduider, na a r.

gam saka: naar boven, gam pao: naar beneden;

gam da ë: naar den landkant, gam lawe: naar de zeezijde; ga m mahek: naar hier, hier heen.

Met dezen richtingaanduider worden gevormd:

$1^{\circ}$ de aanwijzende bijwoorden van hoeveelheid en hoedanigheid en dit op de volgende wijze:

na: deze dit, gam na: aldus, dusdanig, zooveel als dit, deze; di, die, dat, gam di: alzoo, zoodanig, zooveel als die, dat; De versterkte vormen hiervan zijn gam na běnah; gam di bědih; gam na benah he; gam di bedih he.

$2^{\circ}$ 't vragend bijwoord van hoedanigheid:

gam do: hoe? hoedanig? samengesteld uit gam + do welk laatste de befeekenis heeft van $1^{\circ}$ to $\mathrm{ch}, 2^{\circ}$ waar? $3^{\circ}$ dan; rinne do nang môn: hij toch mijn vriend, d. i. hij is mijn vriend; sirra do nim gèb'epsiket: zij toch uwlieder buren;

fido: te waar? waar? fil do? en filim do? van waar?; bà $\mathrm{mah}$ wag'bàna e dà bàtak haik do oek kalak kàn o: als het stoomschip reeds geheel te zien is dan roept gij mij; bà $\mathrm{mah}$ sèget do mà to beh wàg a e: als't vloed is dan duwen we de prauw in zee. 
N.B. Als men vraagt waar gaat gij heen? zegt men niet oek bàik'-gamdo, maar oek bàik'-fi do: gij gaat te waar ? Waar gaat gij geen? ik'fi do: is 'n samengesteld woord en een accenteenheid.

50). lalat: vlak strant, dat bij springvloed nog onderloopt boeroet-eblal'-lalat: land dat geheel en al vlakte is, d.i. 't hiernamaals.

51). doebarbak.

$\mathrm{b}$ a r b a k: samengesteld uit bà $+\mathrm{e} \mathrm{r}+\mathrm{b}$ a k.

Voor zoover mij bekend komt dit prefix er alléen voor in verbinding met $\mathrm{b} a \mathrm{k}$ en beteekent e rbak: hier achter gelaten (op plaats van spreker).

Là betoen dibědih he ${ }^{52}$ ) g'emtoeat ${ }^{53}$ ) sà dàegoeh

Ten tijde diezelfde oude-man 'n nam nak kòkol ${ }^{54}$ ) pà dàik'-tàgah-hèt $\mathrm{ak}^{55}$ ).

z'n draagmandje om ging-ebben.

52). Là betoen dibědih he.

dibědih samengesteld uit di: die, dat + b e : zijnde, $+d i$ die, dat $+h$, suffix verb. vorming; dibědih: diezelfde, datzelfde; labetoen dibědih: op dien zelfden tijd, là betoen dibedih he: op tijd er van die zelfde den, op dien zelfden tijd, ter zelfder tijd; àn at dibědih: dat zelfde kind, àn a t dibědih he: hetzelfde kind; wàgar dibĕdih: diezelfde prauwen, wàgar dib ̌dih ro: dezelfde prauwen.

bě: 't prefix bě: zijn, zijnde, vormt ook 't bijwoord van tijd: nu: $\mathrm{n}$ aběnah wat eigenlijk ' $\mathrm{n}$ verkorting is van betoen nab̌̌nah tijd ervan deze zijnde deze, dezen tijd, nu; là betoen nab ěn ah he; op dèzen tijd.

Voorts komt 't prefix b e: zijnde, nog voor in enkele samenstellingen: b ̌n ewak: van tewah: weten, kennen, b ̌newak : kenbaar zijn voor, duidelijk zijn voor, aan; helder zijn voor, aan; běnima: zijnde nima: der familie van moeders zijde; dus eigen; mar'běnima: eigen stam, ook naam der vrouw, die men volkomen in overeenstemming met de huwelijks 'adat gehuwd heeft. Mà r a h: onderstamdeel.

't Prefix be vormt van enkele imperativa, verba act. transt.

tè foe h: lossen, los 'n pand; bě nè fo ef: lossen, act. transt. iets; tà ho $\mathrm{h}$ : bevelen iets mede te brengen, afspreken; (plaatsen, stellen, Mal. ta roeh) b enàhoeh: bevelen mede te 
brengen iets; b ěna oek: iemand iets bevelen mede te brengen, afspreken met iemand iets mede te brengen.

53). g'emtoeat: samengesteld uit gèbah: mensch, emtoeat: oud, (adject.) oud-man; gèb'emtoeat: oude heer, vader; fin'emtoeat: (fina, vrouw) oude vrouw, moeder; gèbah emtoeat: oude man; gèbah emtoeat sà: 'n oude man, 'n oud mensch;

54). kòkol: 'n kleine draagmand, dien men aan 'n koorde of touw over den schouder draagt om 't een of ander in mede te nemen of er schelpdieren in te verzamelen. Kinderen dragen zulke draagmandjes met 'n draagband om 't voorhoofd.

55). dà ik'-tàgah-hét a k: ikoh: gaan + tàgah: recht ergens op af gaan, met 'n doel zijn, bedoelen met, hètak: ebben, droog worden, terugloopen van 't water, ik'tàgahhètak: naar 't droog geloopen strand, of 'n droog geloopen koraal of zandbank gaan om daar te visschen of schelpdieren te zoeken.

Là betoe Kà Lampo dàkitah he rin dà eprépak Toen Kà Lampo zag hem hij zeide tot fèneh: g'emtoeat e! gammahek là koe òsoh zeggende: oud'man! naar hierheen dat gij binnengaat sàbòbòbok bah na là à ik'esteïh ${ }^{56}$ ) penik, bàmah 'n oogenblikje hier dat ik ga gevoegdoen eerst indien moh do jàko esteïh-bâk Toean Ko Latoe nak niet dan ik gevoegdoen-hier Meneer-de-Vorst van hem èroengan ne.

kot het.

56). esteïh: z'n gevoeg doen, poepen; esteïk: ergens op poepen, bepoepen. etheїh: idem. mёmeïh: (H. Pi.) rěmeïh, (Kbb.) meïh (Sap. N. Har.)

Gamdi g'emtoeat di dàòsoh fidi ěroengan Alzoo oud' man die binnengaan te daar kot la len ne toe Kà Lampo dàsoebah toe binnenste er van het en Kà Lampo ging naar buiten en $\mathrm{d}$ à hèk a h.

vluchtte.

Soep-soepan do àtar pol'pa di doekadoek toe 's Morgens vroeg dan slaven veertig die kwamen en 
doelébah g'emtoeat di e pà doepòlok ke, boe droegen oud' man diè om verdrinken hem maar g'emtoeat te dàlaoen fèneh: oreh kàneh! àtar oud' man de jammerde zeggende ach arme ik! slaven pol'pa jàko do Kà Lampo mélah, ${ }^{57}$ ) toe Kà Lampo veertig $i k$ toch Kà Lampo niet en Kà Lampo dàhèkah haïk.

vluchtte reeds.

Boe àtar pol'pa di doesàdeh fèneh: mélahgah Maar slaven veertig die antwoordden zeggende ' $t$ is niet waar kaë do Kà Lampo rèsek ${ }^{58}$ ) ke; kaë niak kami

gij toch Kà Lampo inderdaad het, gij bedriegen ons(excl.). Béko sir doeik'pòlok g'emtoeat te. Vervolgens zij gingen verdrinken oud' man den.

57). mèlah: niet waar, (Mal. boekan).

mèlah gah: versterkte vorm, 't is niet waar.

gah: nadruksaanwijzer, die in de grove spreektaal veelvuldig gebruikt wordt, tevens bij 'n verbod of bevel om hier op den nadruk te leggen. ikoh gah! ga! ga toch!

58). rèsek: voorwaar, juist; rès-rèsek: versterkte vorm; Bisoek fil di Kà Lampo dàik'fö̈h fidi màsi e.

Daarna Kà Lampo ging-baden te daar zee de. Là betoe rin dàolih haïk rin dàëprépak làhah Toen hij te huis gekomen was hij zeide tot Toean-Ko-Làtoe e fèneh: Toean-Ko-Làtoe, nam «Meneer-de-Vorst» den zeggende: Meneer-de-Vorst, uw àtar-pol'pa doepòlok kàno bébetah ${ }^{59}$ ) fidi nam slaven veertig verdronken mij geraakt te daar uw àma-nitoe ${ }^{60}$ ) sirro nam ina-nitoe noen eskàkoet ${ }^{61}$ ) te. vader-wijlen en uw moeder-wijlen hun dak het.

59). b ̌̌betah: geraakt, getroffen, v. d. juist, precies. Reduplicatie.

In geval reduplicatie heeft bij woorden, die met 'n consonant beginnen herhaling van de eerste lettergreep plaats met dien verstande, dat de vocaal in de eerste lettergreep veranderd wordt in 'n e. betah, běbetah; tewah, te'tewah; fòlon : fĕfòlon enz.

Begint ' $n$ woord met 'n klinker dus inderdaad met 'n hamza, 
dan geschiedt de reduplicatie door $\mathrm{k}$ met den veranderden klinker in $e$ voor 't geheele woord te plaatsen.

alan, kěalan; ikoen, kěikoen; etan, kěetan; enz.

Reduplicatie van actieve of actief-transitieve werkwoorden vormt van deze verba deelwoorden, die 'n adjectieve beteekenis hebben en aantoonen, dat de werking in 't grondwoord bedoeld op 't woord dat door 't deelwoord nader bepaald is wordt toegepast of, dat die werking er door wordt verricht naar dit in 't zinsverband blijkt.

$\mathrm{a} l \mathrm{ah}$ : oogsten, kěalah: geoogst wordend; àpih: klemmen, kěà pih: geklemd wordend, in den klem zittende; betah, raken, treffen, begrijpen; běbetah: geraakt, getroffen, begrepen; van daar, juist, precies: $\mathrm{b} a \mathrm{~b} \mathrm{a} \mathrm{h}$ : op den heup dragen, b ébà$\mathrm{b} \mathrm{ah}$ : op den heup gedragen wordend; à $\mathrm{n} \mathrm{at} \mathrm{b}$ ๕ bà bah: kind, dat men bezig is op den heup te dragen; bodih: omvallen, běbodih: omgevallen; difoek: verdwijnen, verloren gaan; dedifoek: verdwenen, verloren; dereh; stillen van wind, regen, dedereh: gestild; eoek: boos, vertoornd zijn op, kěeoek: gèb'keeoek, mensch waarop men boos, vertoornd is; fòtoh: kerven, fefòtoh: gekorven wordend; gekorven; tabàkoe fèfòtoh: gekorven tabak; gètek: bezwijken, ge egè tek: bezweken, sibih esnà pak gèb'gĕgètek di e : help dien bezweken mensch eventjes; goetoek: afbreken, g eg o etoek: afgebroken; hawih: rooven, h ̌hawih: geroofd wordend; eptànak gam mahek iër hěhawih ro: breng de geroofd wordende goederen hierheen; hisih: afplukken, hěhisih: afgeplukt; ibik: oppassen, kěibik: opgepast wordend; ipik: in pand nemen, kěipik: in pand genomen wordend; kalik: iets ergens in of uitgraven, k ̌kalik: ergens in of uitgegraven, uitgegraven wordend; katoek: iets zenden aan iemand, kěkatoek: gezonden wordend: làh ak: leenen, in leen nemen; lelà hak: geleend worden; là ta h: hakken iets, 1 lelàt a h: gehakt; 1 òlok: aanspoelen, 1 lelòlok: aangespoeld; loelah: vlammen, léloelah: vlammende; màlih: lachen, $\mathrm{mermàlih:} \mathrm{lachende;} \mathrm{màn} \mathrm{eh}$ : eedzweren, $\mathrm{m}$ ěmàn $\mathrm{eh}$ : eedzwerend; midih: spelen, m e midih: spelend; mòtih: koude koortsen; mermòtih: koude koorts hebbend; na noek: gissen, meenen, veronderstellen, nèna noek: gegist, gemeend, verondersteld wordend; neïk: bewaren, wegleggen, nе̌neïk: bewaard, weggelegd; nèmah: hoesten, nе̌nemah: hoestend; 
ngihih: kittelen, ngĕngihih: gekitteld wordend; òdok: opsporen, kěòdok: opgespoord wordend; ogih: krabben, kěogih: gekrabd wordend; òmok: vleesch in bladeren gewikkeld tusschen gloeiende steenen roosteren, kě ò $\mathrm{mok}$ : aldus geroosterd wordend; e n jòm ot: geroosterd; ò s o k: iets ergens binnen brengen, k è̀ sok: binnengebracht wordend; pàlih: vlechten, pépàlih: gevlochten wordend; pà poeh: koken, pépà poeh: gekookt wordend; pépek: plat drukken, pépépek: plat gedrukt wordend; pemoeh: in den bek dragen, pépemoeh: in den bek gedragen wordend; $r$ àhoh: lekken van 'n huis; rĕràho h: lekkend; ràkah: betasten, rĕrà ka h : betast wordend; sanoh: uitstrekken den voet, š̌sanoh: uitgestrekt wordend; uitgestrekt zijnde; uitgestrekt; siwah: uitpeuteren, sěsiwah: uitgepeuterd wordend; uitgepeuterd; soök: strikken, sц̌sö̈k: gestrikt wordend, in den strik zittend; tà h a h: omhakken, tětà hah: omgehakt wordend; omgehakt; tedek: sluiten 'n deur; tětedek: gesloten wordend, gesloten zijnde, gesloten; temak: aantrekken 'n broek; tětemak: aangetrokken wordend, zijnde, aangetrokken, gedragen; oelih: uitpeuteren, kěolih: uitgepeuterd wordend, uitgepeuterd; wanoh: fluiten, wè wa noh: gefloten wordend, gefloten; werik: achterlaten, wěwerik: achtergelaten worden, achtergelaten.

Woorden door reduplicatie van substantiva op dezelfde wijze gevormd, als dit bij de verba geschiedt beteekenen, voorzien zijn, hebbende, dragende dat wat in 't substantief is uitgedrukt. à lan: kant, kẹalan: 'n kant, kanten hebbend, gekant; àsan: kieuw kĕàsan: kieuwen hebben, van kieuwen voorzien, gekieuwd; eli: grot, kěeli: 'n grot, grotten hebben; eran: fakkel, kěeran: 'n fakkel dragend, van 'n fakkel voorzien; etan: teeken, kěetan: van 'n teeken voorzien, 'n teeken dragend, beteekend; ikoen: staart, kěikoen: 'n staart dragend; itik: bliksem, kěitik: met bliksem, weerlicht zijn (de lucht). òkon: huid, kěòkon: 'n huid hebbend, dragend, oban: roeibank, kěoban: van roeibanken voorzien zijn, roeibaken hebben; oenen: pit, hart van 't hout, kěoenen: 'n pit hebbend; oeka: bamboe, kěoeka: van bamboe voorzien, met bamboe begroeid.

bоen: staart, bеъьоеn: 'n staart dragend; dimoe: nevel, dédimoe: van nevel voorzien, beneveld; fòlon: haar, fefòlon: 
van haar voorzien, behaard; gà la n: armring, g eg à la n : 'n armring dragend, hèset: wand, hèhèset: van wanden voorzien, bewand; kàt a: broek, kěkàta: 'n broek dragend, gebroekt; kàdan: been, poot; kěkàdan: beenen, pooten hebben; là: zeil, lelà: van zeil voorzien, maën: handvat, gevest, měmaën: voorzien van 'n handvat, gevest; nawa: idjoek, nĕnawa: van idjoek voorzien; panen: vleugel, pepanen: vleugels hebbend, gevleugeld; ràki: lichaamsvuil, rěr à ki: lichaamsvuil hebbend, sodin: gewei, sěsodin: gehoornd, gewei dragend; wad oet sěsodin: hertebok; tètoen: kaap, tětètoen: 'n kaap hebben; wàlan: nerf, wěwalan: nerven hebben, generfd;

60 ). àma-nitoe. nitoe: wijlen. Substantief. nitor: wijlen subst. pluraris, voorvaderen, $\mathrm{n}$ a $\mathrm{m}$ à $\mathrm{m}$ a $\mathrm{n}$ i to $\mathrm{e}$ : uw vader-wijlen, wijlen uw vader; nitoe fin' toeat Moeal kaoenne: wijlen oude vrouw Moeal's graf.

61). eskàk oet: dak afgeleid van kà k o e berg.

e skà koet: wat op 'n berg gelijkt, v. d. dak.

't Prefix es wordt gebezigd tot 't. vormen van:

a. substantiva gelijkend op 't grondwoord.

eskèten: ruggegraad; eskòkon: rasp.; eskoeroen: strot, keel; es la ît: wilde pinang; es la oet: boete; eskàran : penwortel; e skàpil: vuurtang van bamboe; eskẻhan: strot; eslikoet: kamer; eslèlet: afsluitingsteeken; esrè pet: beschikkingsteeken; esniken: logieën; eslěhen: kloof, bergkloof; esmaoen; roode mier; espanen: verkoudheid; espengen: blaas; espera: geweer.

b. Verba frequentativa.

eskihih: krabben, eskòhoh: raspen, es berik: sprenkelen, esboeah: toe dekken, esboeëk: uitstrooien, esbaroeh: verven; esbeïk: afsnijden, esbobik-esneat: afscheid nemen; esgä h: loslaten; eskelah: aan schijfjes snijden; esgeoek: naar eigen wil, willekeurig handelen; esgè la h : braden koffie of maïs of katjang; eskòfih : omstralen (door 't licht); esgerah: in 'n selendang dragen; esgifeh: schoppen met de voorzijde van den voet; eslébo'ek: indompelen, eslimah: aanroepen van de Godheid; esmòsah : bestrijken; esleoeh : doorgaan en niet aanleggen; esmàrah: aan doen, aanleggen; e s m ò $\mathrm{r}$ o h : heet ijzer vast grijpen bij godsgericht; esnè pah: medicineeren 'n meisje om haar spoedig geschikt te doen zijn 
voor 't huwelijk; esngètak: vast stellen, 'n besluit nemen; es pèleh: smijten, esngòik: mikken; espidoh: snot weggooien; espònoh: beslechten; eswaroeh : verknoeien ; estèfoh: pissen; estoefak: stooten tegen; espàhih : met 't scheenbeen slaan tegen den kuit en enkel van 'n ander; esràhih: uitgraven met de handen, esperak: wurgen; esroegah: met 'n scherp voorwerp naar boven steken; e s wàg e h : vervloeken met ziekten; e s $\mathrm{m}$ à $\mathrm{ke} \mathrm{h}$ : vervloeken met vasten datum; estoebik: sprongen maken, springen; estiken: kraken, knapperen.

c. acadenteele verba.

e skòpih: losschieten van den pal in den strik voor buideldieren, esgeboeh: plotseling dood blijven.

d. adjectiva.

esb'et: onnut: eskà pit nauw, eng, eslàdat wijd uit elkander; esmèhen: nauw van 'n broek; estiak: gespannen van den buik. e. Adverbium.

eskèle : bijna.

Toe nam ina sirro nam àma doeëprèpak fèneh: En uw moeder en uw vader zeiden zeggende kaë hèlen-hélen gam lawek.

gij heel gauw naar zee gaan.

Bèko Toean-Ko-Làtoe dasioek nak àtar-pol'pa Daarna Meneer-de-Vorst zond zijn slaven veertig fèneh: kim gà roeh nang ěroengan sa. Gamdi zeggende gij lieden maakt mijn kooi 'n. Al zoo nak àtar pol'pa di doepoenah ěroengan hij bezitter er van slaven veertig die maakten kooi sà toe doeòsok Toean-Ko-Latoe e fidi éroengan 'n en deden in Meneer-de-Vorst den te daar kooi la lenne, bèko sir doeëptànak ke gam lawek. binnenste zijn, daarna zij brachten hem naar zee gaan.

Bèko sir doesàhih etah esnègen lawe-lawe

Daarna zij schepten komen aan tot aan ver in zee toe sir doëprépak fèneh:

en zij zeiden zeggende:

"pòlok ke fina bèkah!" doeduiken hem te hier maar!

Gamdisir doepòlok Toean Ko-Làtoe e. Alzoo zij deden duiken Meneer de Vorst den. 
362 TIJL UILENSPIEGEL VERHAAL IN DE BOEROETAAL.

Toe Kà Lampo dàolih toe dàalah Toean Ko Làtoe En Kà Lampo ging naar huis en nam "Meneer-de-Vorst nak fin'har ${ }^{62}$ ) ro toe Kà Lampo emsikan hij bezitter ervan vrouwen de en Kà Lampo zelf dà poena Toea n-Ko-Là to e. werd Meneer-de-Vorst.

62). fin'hà: samengesteld uit fin a + há: getrouwde vrouw, echtgenoote. Dit laatste als men tot 'n gehuwd man over z'n wederhelft spreekt.

gèb'há: samengesteld uit gèbah + há: gehuwde man, echtgenoot over of van hem sprekend tot z'n vrouw.

De beide echtgenooten zeggen ook nang fin' há, en nang gèb' há.

In de Fènar pòlo: ('t Masrètěsche) wordt 't hoofd van 'n onderstamdeel ook gèb' há genoemd. 